\title{
Goddard Cumulus Ensemble Model. Part II: Applications for Studying Cloud Precipitating Processes and for NASA TRMM
}

\author{
JOANNE SIMPSON ${ }^{1}$ and WEI-KUO TAO 1 \\ (Manuscript received 21 September 1992, in final form 15 January 1993)
}

\begin{abstract}
The response of cloud systems to their environment is an important link in a chain of processes responsible for monsoons, the Mei-Yu frontal depression, El Nino-Southern Oscillation (ENSO) episodes and other climate variations (e.g., 30-60 day intra-seasonal oscillations). Numerical models of cloud properties provide essential insights into the interactions of clouds with each other, with their surroundings, and with land and ocean surfaces. Significant advances are currently being made in the modeling of rainfall and rain-related cloud processes (e.g., latent heat release), ranging in scales from the very small up to the simulation of an extensive population of raining cumulus clouds in a tropical- or mid latitude-storm environment. Cloud models can also be used to convert the radiances received by cloud-observing microwave radiometers into rainfall rates. Remote sensing of cloud-top properties by high-flying aircraft bearing microwave and other instruments is now beginning to provide powerful tests of these models, particularly when these observations are augmented by simultaneous ground-based radar measurements.

The Goddard Cumulus Ensemble (GCE) model is a multi-dimensional non-hydrostatic dynamic/microphysical cloud model. It has been used to simulate many different mesoscale convective systems that occurred in various geographic locations. In part I (Tao and Simpson, 1993), a full description of the GCE model has been presented. In Part II (this paper), we provide an overview highlighting GCE model applications to the study of precipitation processes and to the Tropical Rainfall Measuring Mission (TRMM), a joint satellite project between NASA. (U.S.A.) and NASDA (Japan).
\end{abstract}

\section{INTRODUCTION}

Precipitating cloud systems are the key link in the hydrological cycle on planet Earth. More than half of global precipitation originates from clouds driven by moist convective

1 Mesoscale Dynamics and Precipitation Branch, Laboratory for Atmospheres, NASAGoddard Space Flight Center, Greenbek, MD 20771, U.S.A. 
processes. Cumulus cloud systems, as well as producing life-sustaining rain, carry out energy transactions that are crucial to global circulations and their variability (Simpson, 1988). Most severe atmospheric weather events, such as tropical hurricanes/typhoons, tomadoes, electrical storms, downbursts, and flash floods are convectively driven.

Generally speaking, the role of clouds in the atmospheric general circulation and global climate is two-fold. On the one hand, clouds owe their origin to large-scale dynamical forcing, radiative cooling in the atmosphere and turbulent transfer processes between the ground and the atmosphere (e.g., the ransfer of heat and moisture from the ocean to the atmosphere). On the other hand, the latent heat from precipitating clouds provides three-fourths of the energy received by the atmosphere. Clouds also serve as important mechanisms for the vertical re-distribution of momentum, trace gases (including Greenhouse gas, $\mathrm{CO}_{2}$ ) and sensible and latent heat on the large-scale. They also influence the coupling between the atmosphere and the earth's surface as well as the radiative and dynamical-hydrological balance. Recent numerical experiments show that clouds and their associated radiative transfer processes significantly affect the predicted large-scale circulation . At present neither diabatic heating effect (precipitation latent heat release or radiative transfer by clouds) is well simulated in large-scale models. Thus, improving the representation of clouds and cloud processes in GCMs and climate models is crucial to better understand and predict the large-scale circulation and short-time climate changes (Simpson et al., 1988).

The Goddard Cumulus Ensemble (GCE) model is a multi-dimensional non-hydrostatic dynamic/microphysical cloud-scale model. It has been used to provide essential insights into the interactions of clouds with each other (Tao and Simpson, 1984; 1989a), with their surroundings (Soong and Tao,-1980; 1984; Tao and Soong, 1986; Tao, Simpson and Soong, 1987; Tao and Simpson, 1989b), with long wave radiative transfer processes (Tao et al., 1991, 1993), and with ocean surfaces (Tao et al., 1991; Lau et al., 1993; Sui et al., 1993a and b), and cloud draft structure and trace gas transport (Scala et al, 1990; Pickering et al., $1991,1992 a, b, c)$. The GCE model has also been used to convert the radiances received by cloud-observing microwave radiometers into predicted rainfall rates (Simpson et al., 1988). Remote sensing of cloud-top properties by high-flying aircraft bearing microwave and other instruments is now beginning to provide powerful tests of the GCE model, particularly when such observations are augmented by simultaneous ground-based radar measurements (Adler et al., 1991; Yeh et al., 1992). The GCE model has also been used to study the distribution of rainfall and inferred heating (Tao et al., 1990; 1993).

A full description of the GCE model as well as several sensitivity tests associated with assumptions used in the model has been presented in Part I (Tao and Simpson, 1993). Thus, only a brief description of the GCE model will be given in Section 2. Applications of the GCE model to the study of cloud precipitating processes (cloud interactions and mergers, clouds and their feedback on the large-scale circulation, cloud-radiation interaction, convective and stratiform interaction, horizontal momentum transport by cloud systems, and cloud-chemistry interaction) will be reviewed in Section 3. In Section 4, highlights of the GCE model applications to the Tropical Rainfall Measuring Mission (retrieval of the latent heating profile, and development of rain retrieval algorithms) and climate study will be presented.

\section{GODDARD CUMULUS ENSEMBLE MODEL}

The Goddard Cumulus Ensemble (GCE) model is a multi-dimensional non-hydrostatic cloud-scale model. A stretched vertical coordinate (height increments from 220 to 1050 m) with 31 grid points is used in order to maximize resolution in the lowest levels of the 
model. The model top can be $20-25 \mathrm{~km}$. For typical two-dimensional model simulations, 512-1024 grid points are used in the horizontal (using 250 to $1000 \mathrm{~m}$ resolution). In the three-dimensional model, however, the current computer limits us to about $200 \times 60$ or $120 \times 120$ grid points (using 1000 to $2000 \mathrm{~m}$ resolution) in the horizontal. For line-type convection, an open-type lateral boundary condition is used along the $\mathrm{x}$-axis in the direction perpendicular to the line convection and a periodic lateral boundary condition is applied along the $y$-axis. In actual GCE model applications, the number of grid points in each simulation can be adjusted for specific purposes and for considerations of computer time.

The cloud microphysics include a parameterized Kessler-type two-category liquid water scheme (cloud water and rain), and parameterized Lin et al (1983) three-category ice-phase schemes (cloud ice, snow and hail/graupel). Short-wave (solar) and long wave (infrared) radiation parameterizations as well as a subgrid-scale turbulence (one-and-a-half order) scheme are also included in the model. A detailed description of the GCE model has been presented in Part I (Tao and Simpson, 1993).

\section{APPLICATIONS OF THE GODDARD CUMULUS ENSEMBLE (GCE) MODEL TO UNDERSTANDING PRECIPITATING PROCESSES}

\subsection{Cloud Interactions and Mergers}

It has been recognized that the largest and most persistent convective clouds are often formed by the merging of two or more adjacent cells. The mergers usually yield more than an order of magnitude more precipitation than unmerged cells (Simpson et al., 1980). However, the physical mechanisms which effect the merging process are not clearly specified through observational studies, largely because of the difficulty of measuring the air circulations in and around cumulus clouds. Westcott (1984) reviewed observational analyses of mergers in detail, and also raised some key questions conceming the mechanisms involved. From observational studies, several processes have been proposed as important in merging events. These processes fall into two main categories. The first involves addition of moisture to neighboring air, thereby reducing dilution by entrainment. Moistening of the cloud environment can be accomplished in several ways. One source of moisture is precipitation falling from an overhanging canopy which produces a favorable environment for new convective growth. Dissipation of previous and nearby clouds also provides a moister, more favorable environment. The second category involves dynamic processes which enhance low-level convergence leading to new growth and merging. Low-level convergence can be enhanced by (1) collision of downdraft outflows; (2) differential motions of cloud masses; and (3) hydrostatic and non-hydrostatic pressures response within the boundary layer.

A two-dimensional version of the GCE model was used with a GATE data set to study cloud interactions and merging (Tao and Simpson, 1984). Over two hundred groups of cloud systems with a life history of over sixty minutes were generated under the influence of different combinations of the stratification and large-scale forcing (through a total of 48 numerical experiments). The GCE model results demonstrated the increase in convective activity and in amount of precipitation with increased intensity of large-scale forcing (lifting). Based on the GCE model results, the most unfavorable environmental conditions for cloud merging are 1) less unstable stratification of the atmosphere and 2) weaker large-scale forcing. One advantage of the model simulations is that the model can be rerun in order to investigate the sensitivity of its results to various physical processes. Figure 1 shows a pair of runs using identical initial conditions. The only difference is that the drag force of rain water in the vertical equation is set to zero in the sensitivity test. The absence of the drag force can lead to a delay in either the onset or the weakening of the downdraft below the cloud. The new convective cell, marked as A3 in the merged situation (Figure 1a), did not occur in the run with weaker downdraft. 

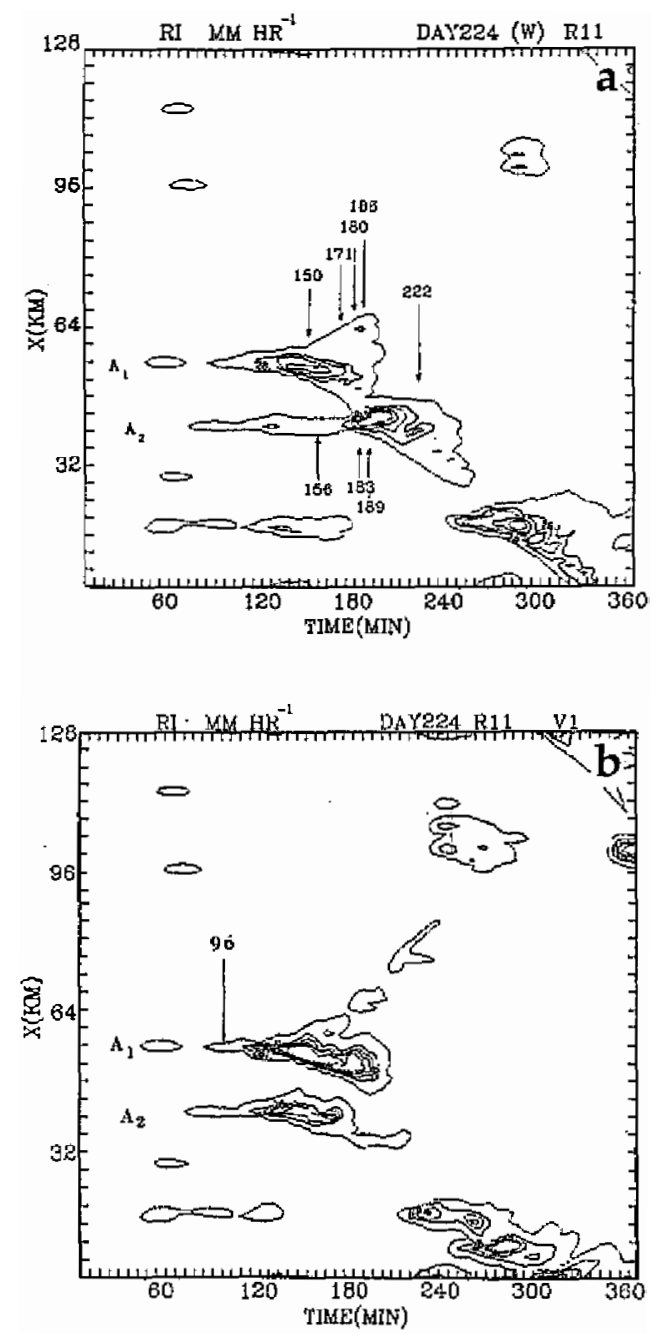

Fig. 1. (a) Time sequence of estimated surface rainfall rate over the horizontal domain. This case involves the interaction between two convective clouds $\left(A_{1}\right.$ and $\left.A_{2}\right)$ in different stages of their life cycles. (b) As in (a) except for the numerical experiment with the process of setting the drag of rain water to zero in the $\mathrm{w}$-momentum equation. This process starts at $t=96$ min and is limited to the area covered by clouds $A_{1}$ and $A_{2}$. The contour interval is $25 \mathrm{~mm} / \mathrm{hr}$.

Later, a total of nine three-dimensional experiments were made using the same GATE data set (Tao and Simpson, 1989a). Ten merged systems involving precipitating clouds were identified. Eight of these ten mergers involved two previously separated clouds; seven of these lie along a line roughly parallel to the initial environmental wind shear vector (called parallel cells, see Figure 2). Only one merger lies along a line roughly perpendicular to 
the wind shear vector prior to the merging (called perpendicular cells, see Figure 3 ). The dominance of parallel cells is consistent with observations in FACE and GATE (Simpson et al., 1980; Turpeinen, 1982). The remaining two systems involve three clouds and are a combination merger of parallel and perpendicular cells. It was also found that a cloud bridge, which consists of a few low-level cumuli which develop and connect the clouds before the merger is detected on radar, occurs in most of the simulated merger cases (This phenomenon was also well-simulated in the 2-D model). Both backward and forward air parcel trajectory analyses (Figure 4) were performed. Forward air parcel trajectories are computed using grid points located in the merging area. Then, a backward trajectory calculation is performed to locate the origins of the high-rising parcels. These trajectory analyses show that the highrising air parcels at the bridge area are strongly affected by either one or two interacting cold outflows. The GCE model studies suggest that the primary initiating mechanism for the occurrence of a precipitating cloud merger is the cloud downdrafts and their associated cold outflows as proposed by Simpson (1980). A significant difference between the simulated parallel and perpendicular cells is that the latter cells are usually situated closer to each other $(5-6 \mathrm{~km})$ prior to merging than the former $(10 \mathrm{~km}$ or more). An explanation for this difference is that the direction of individual cell movement as well as the direction of cold outflow are predominantly directed down shear.

\subsection{Response of Deep Cloud Systems to Large-Scale Processes in Various Geographic Locations}

\section{(a) Heating and Moisture Budgets}

In diagnostic studies (e.g., Yanai et al, 1973), it is customary to define the apparent heat source $Q_{1}$ and the apparent moisture sink $Q_{2}$ of a large-scale system by averaging horizontally the thermodynamic and water vapor equations as:

$$
\begin{aligned}
& Q_{1}=\bar{\pi}\left[\frac{\partial \bar{\theta}}{\partial t}+\vec{V} \cdot \nabla \bar{\theta}+\bar{W} \frac{\partial \bar{\theta}}{\partial z}\right] \\
& Q_{2}=-\frac{L_{v}}{C_{p}}\left[\frac{\partial \bar{q}_{v}}{\partial t}+\vec{V} \cdot \nabla \bar{q}_{v}+\bar{W} \frac{\partial \bar{q}_{v}}{\partial z}\right]
\end{aligned}
$$

$Q_{1}$ and $Q_{2}$ can be calculated either from observations or from grid values in a large- or regional-scale prediction model. $Q_{1}$ and $Q_{2}$ can directly relate to the contributions of cloud effects which can be explicitly estimated by the GCE model (Soong and Tao, 1980; Tao, 1983; Tao and Soong, 1986; Tao and Simpson, 1989b):

$$
\begin{aligned}
Q_{1} & =\bar{\pi}\left[-\frac{1}{\bar{\rho}} \frac{\partial \bar{\rho} \overline{w^{\prime} \theta^{\prime}}}{\partial z}+\bar{D}_{\theta}\right]+\frac{L_{v}}{C_{p}}\left(\bar{c}-\bar{e}_{c}-\bar{e}_{r}\right) \\
& +\frac{L_{f}}{C_{p}}(\bar{f}-\bar{m})+\frac{L_{s}}{C_{p}}(\bar{d}-\bar{s})+\bar{Q}_{R} \\
Q_{2} & =\frac{L_{v}}{C_{p}}\left[\frac{1}{\bar{\rho}} \frac{\partial \bar{\rho} \overline{w^{\prime} q_{v}^{\prime}}}{\partial z}-\bar{D}_{q_{v}}\right]+\frac{L_{v}}{C_{p}}\left(\bar{c}-\bar{e}_{c}-\bar{e}_{r}\right) \\
& +\frac{L_{s}}{C_{p}}(\bar{d}-\bar{s})
\end{aligned}
$$



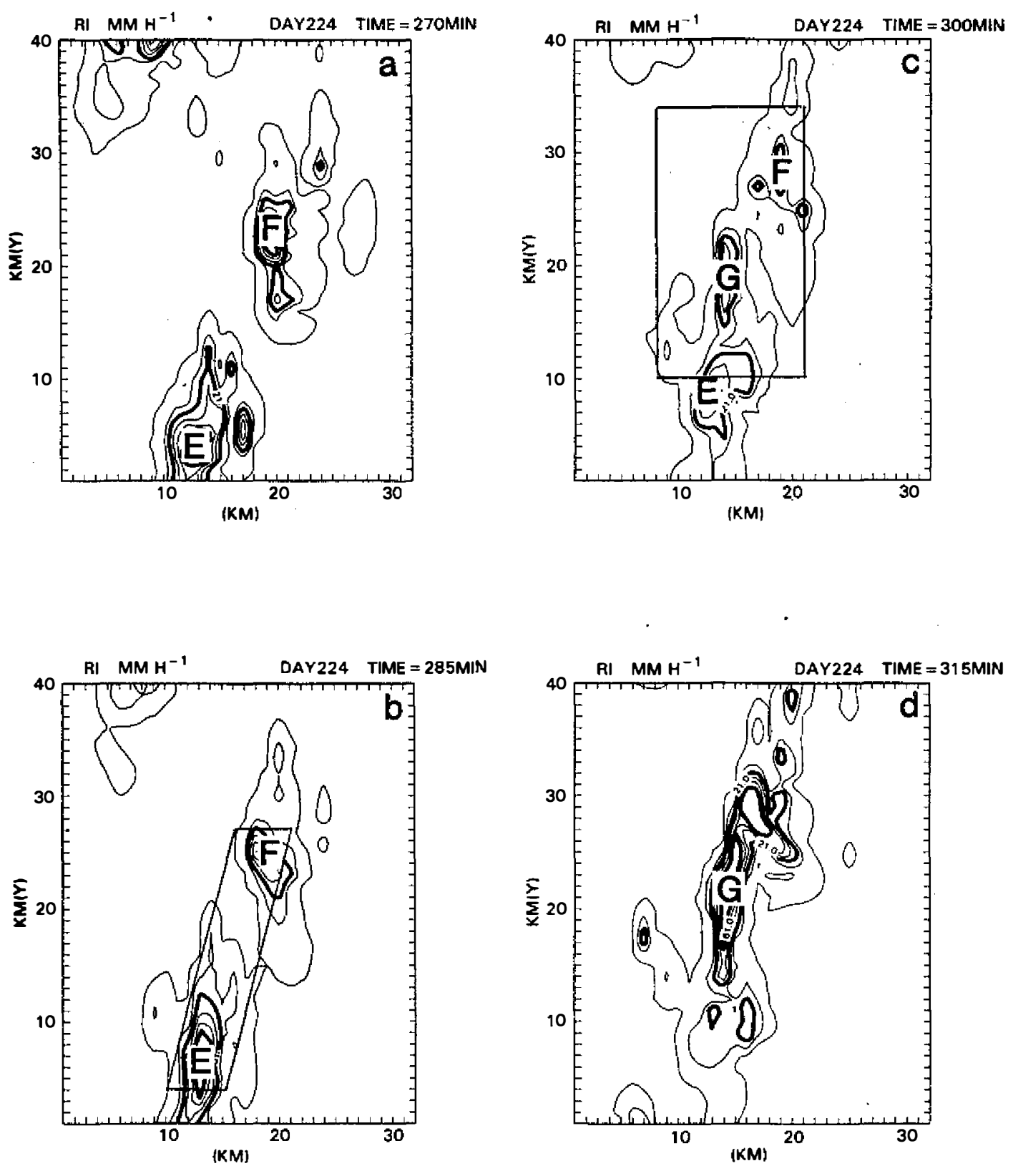

Fig. 2. Estimated surface rainfall intensity over part of horizontal domain at (a) $270 \mathrm{~min}$, (b) $285 \mathrm{~min}$, (c) $300 \mathrm{~min}$ and (d) $315 \mathrm{~min}$ simulated time from a three-dimensional GCE model. The contour interval is $10 \mathrm{~mm} \mathrm{~h}^{-1}$ starting at $1 \mathrm{~mm} \mathrm{~h}^{-1}$. 

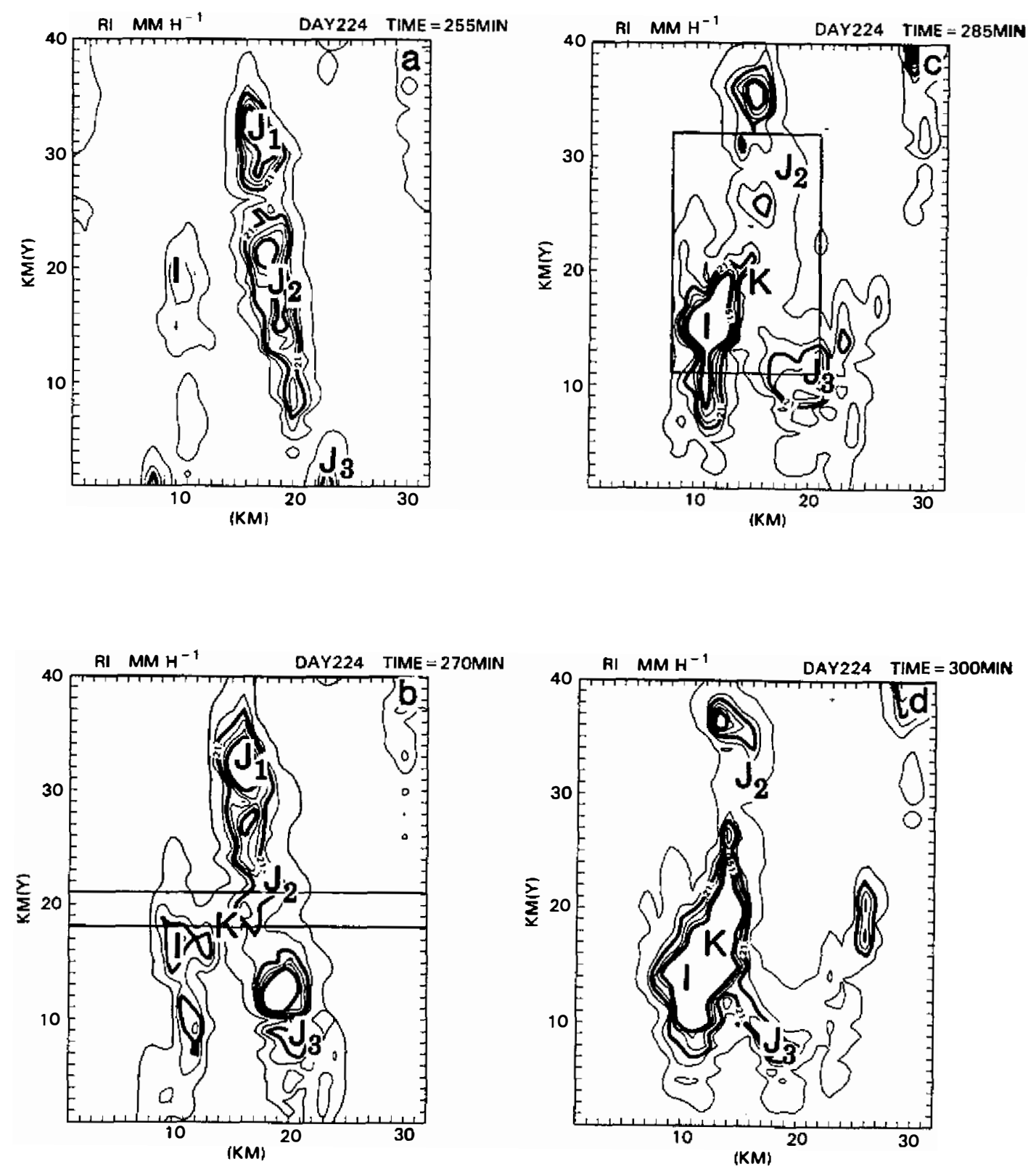

Fig. 3. Same as Fig. 2 except for the case of perpendicular cells. Time is (a) 255 $\mathrm{min}$, (b) $270 \mathrm{~min}$, (c) $285 \mathrm{~min}$ and (d) $300 \mathrm{~min}$. 

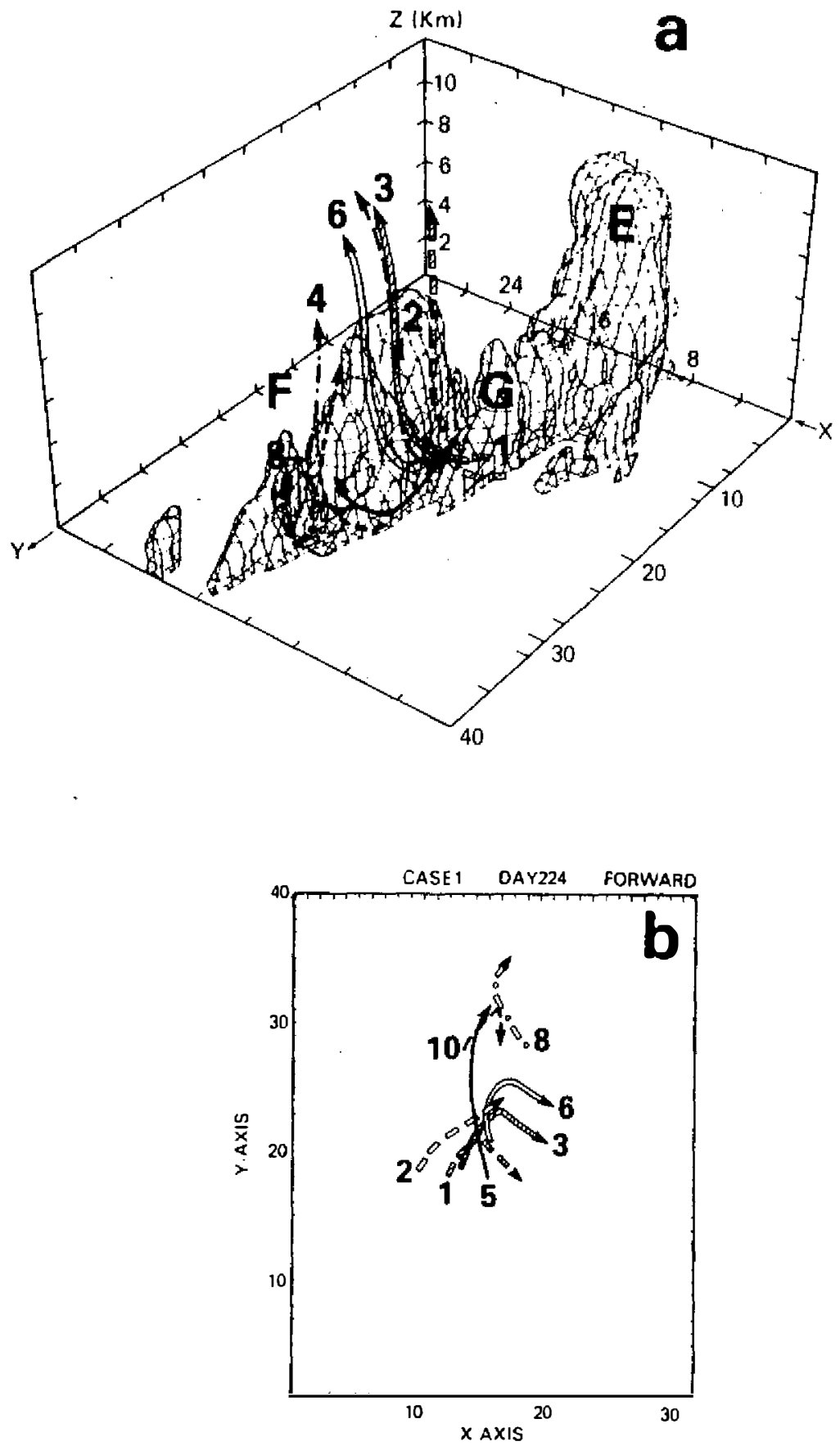

Fig. 4. Depiction of trajectory paths calculated from the evolving three-dimensional model wind fields for the parallel cell case shown in Fig. 2. (a) Threedimensional depiction of upward paths as viewed from NNW, (b) as viewed from the overhead. They are computed forward from $300 \mathrm{~min}$ to $340 \mathrm{~min}$. (c) and (d) are the same as (a) and (b), respectively, except they are computed backward from $300 \mathrm{~min}$ to $270 \mathrm{~min}$. The shaded area in (a) and (c) indicates the three-dimensional depiction of estimated 20 $\mathrm{dBZ}$ iso-surface at $300 \mathrm{~min}$. 

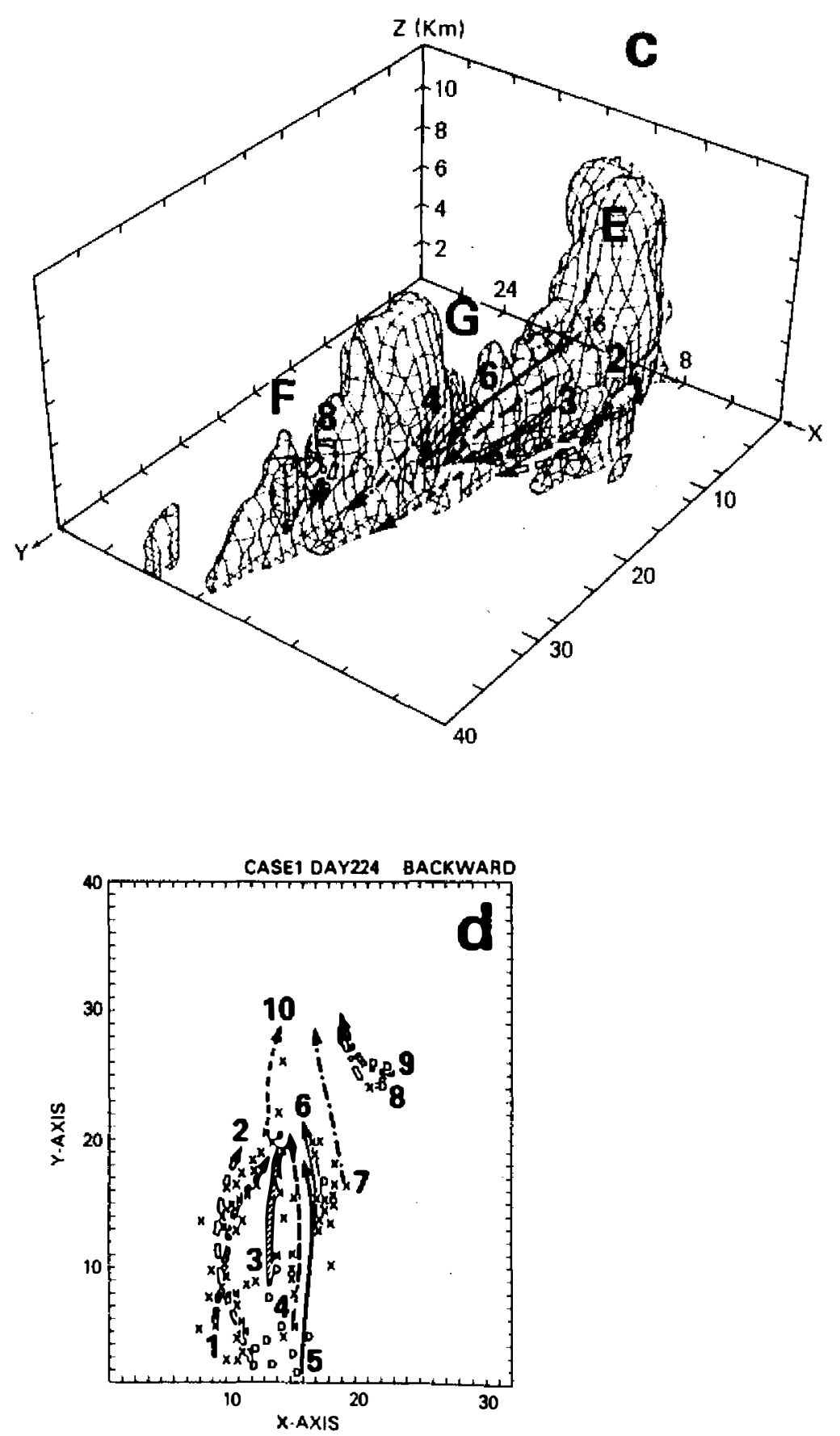

Fig. 4. (Continued.) 
The overbars denote horizontal averages, the primes indicate deviations from the horizontal averages. The variable $\bar{\rho}$ is the density, and $\bar{\pi}=\left(p / P_{\mathrm{oo}}\right)^{R / C_{\mathrm{p}}}$ is the nondimensional pressure, where $p$ is the dimensional pressure and $P_{00}$ the reference pressure taken to be $1000 \mathrm{mb} . C_{p}$ is the specific heat of dry air at constant pressure, and $\mathrm{R}$ is the gas constant for dry air. The variables $L_{v}, L_{f}$ and $L_{s}$ are the latent heats of condensation, fusion and sublimation, respectively. The variables c, $e_{c}, e_{r}, f, m, d$ and $s$ stand for the rates of condensation, evaporation of cloud droplets and raindrops, freezing of raindrops, melting of snow and graupel/hail, deposition of ice particles and sublimation of ice particles, respectively. The term $Q_{R}$ is the cooling/heating rate associated with radiative processes. Also, the first terms on the right-hand side of (3) and (4) are the vertical eddy heat and moisture flux convergences, respectively. The subgrid scale turbulence terms are represented by $D_{\theta}$ and $D_{q}$, and are negligibly small compared to other terms (Soong and Tao, 1980; Krueger, 1988). Eqs. (3) and (4) represent the cloud heating and drying effects, respectively.

The vertical distribution of heating in the stratiform region of MCSs is considerably different from the vertical profile of heating in the convective region (Houze, 1982; Johnson, 1984). The modeled squall system is first partitioned into convective and stratiform regions following techniques developed by Churchill and Houze (1984). The Churchill and Houze separation technique is based on surface precipitation; therefore, two additional criteria have been added in order to further identify those grid points having no surface precipitation and which are not in the clear region. A grid point with no surface precipitation is considered convective if cloud water is present $\left(q_{c}>0.1 \mathrm{~g} \mathrm{~kg}^{-1}\right)$ below the melting layer, or if the maximum updraft exceeds $5 \mathrm{~m} \mathrm{~s}^{-1}$. Both criteria are useful in identifying those regions where convection may be quite active aloft with little or no precipitation at the surface, such as areas associated with tilted updrafts and new cells initiated ahead of organized squall lines (Tao and Simpson, 1989b). The $Q_{1}$ and $Q_{2}$ budgets derived in (3) and (4) are separated into three distinct cloudy regions: convective, stratiform and "non-raining" (the area where rainfall failed to reach the surface beneath the trailing stratiform cloud). Except for the radiative cooling term, the magnitude of each of the terms in the $Q_{1}$ and $Q_{2}$ budgets in clear air were small in comparison to those in the cloudy regions (Tao et al., 1993).

The 2-D version of the cloud ensemble model was first applied to shallow moist convection by Soong and Ogura (1980), and to deep convection by Soong and Tao (1980). Tao (1983) has added the third dimension and Tao and Simpson (1989b) have included ice microphysical processes in the cloud ensemble model. Figure 5(a) shows the vertical profiles of heating or cooling effects of a GATE convective line which was simulated by the three-dimensional model (Tao and Soong, 1986). The heating due to the vertical flux of sensible heat by convective clouds $(\mathrm{F})$ is one order of magnitude smaller than that produced by condensation at most levels. On the other hand, the maximum value of the cooling rate by evaporation (e) is more than half of the heating rate by condensation. This finding implies that the sum of the condensation and evaporation would provide a good approximation of the total cloud heating rate. The cloud heating effect would be considerably overestimated if heating by condensation alone is considered, ignoring cooling by evaporation. Figure 5(b) shows the vertical profiles of moistening or drying effoct due to the clouds. The net vertical flux of moisture by clouds is generally smaller than the rate of condensation or evaporation; but it is not negligible. The corresponding $Q_{1}$ and $Q_{2}$ profiles obtained from the large-scale variables are also shown in Figure 5 for comparison. The model generated heating and drying effects agree well with those estimated from observations.

In the remainder of this subsection and in the following two subsections (3.3 and 3.4), the GCE model-simulated results for both a tropical oceanic (EMEX; Equatorial Mesoscale 
EXperiment) and a mid latitude continental squall line (PRE-STORM; Preliminary Regional Experiment for STORM central) are presented. The ice-microphysical processes and long wave radiative transfer processes are fully included in these two simulations. These two squall lines developed in quite different environments (see Figure 1 in Tao et al, 1993). For example, the CAPE (Convective Available Potential Energy) for the EMEX squall line is much smaller $\left(1484 \mathrm{~m}^{2} \mathrm{~s}^{-2}\right)$ than that of the PRE-STORM case $\left(2300 \mathrm{~m}^{2} \mathrm{~s}^{-2}\right)$. Also, the vertically integrated water vapor contents are quite different:, namely 6.175 and $4.385 \mathrm{~g}^{-1}$ $\mathrm{cm}^{-2}$ for the EMEX and PRE-STORM cases, respectively. A very moist environment in the western Pacific region (WMONEX, AMEX) is quite common.
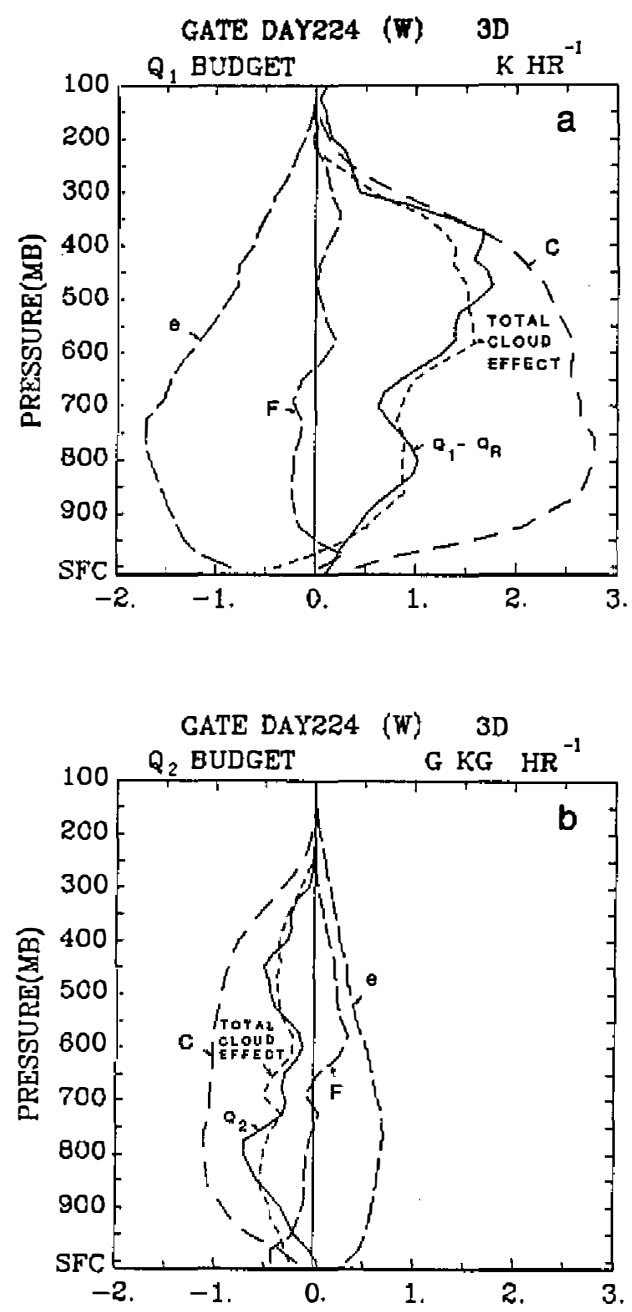

Fig. 5. (a) The vertical profiles of the heating rate by condensation of moisture, $c$, evaporation of liquid water drops, $e$, net vertical flux of the sensible heat, $F$, the total heating rate by clouds and the heating rate estimated from large-scale observations, $Q_{1}-Q_{R}$. (b) The vertical profiles of the moistening rate by condensation of moisture, evaporation from the liquid water drops, net vertical moisture flux, the total moistening rate by clouds and the moistening rate estimated from the large-scale observations, $\left(\mathrm{C}_{p} / \mathrm{L}\right) \mathrm{Q}_{2}$. 
The simulated squall systems capnured several important observed features. For example, an intense leading convective line and a broad stratiform rain region were simulated in both cases. Several well-known features associated with mid latitude squall lines, such as a squall mesohigh, a wake low, and a rear inflow, were also simulated in the two cases. These simulated features are much weaker in the tropical squall sytem than its counterpart in mid latitudes. Another difference is that stratiform rain developed rapidly for the tropical case. The model results also indicate that both the EMEX and PRE-STORM systems propagate by discrete growth of new convective elements ahead of the old cells. New growth originates along the leading edge of the gust front, which is propelled by downdraft air from decaying convective cells. These features have been reported in several field experiments (e.g., GATE, TAMEX, COPT-81 and PRE-STORM).

Table 1 shows the individual components of the $Q_{1}$ and $Q_{2}$ budgets: condensation, evaporation, deposition, sublimation, melting, freezing, vertical eddy (heat and moisture) flux convergence and radiative cooling associated with these two squall cases. These numbers are normalized with respect to their corresponding surface precipitation for comparison purposes. In the convective region of both squall systems, significant heating occurred from the latent heat released by condensation. In contrast, the condensation/deposition was nearly balanced by evaporation/sublimation in the stratiform and in the non-raining regions for the PRESTORM case. A net heating in the stratiform region in the EMEX case is also a reflection of the greater stratiform rainfall generated in the EMEX case. The total amount of melted ice and frozen hydrometeors is comparable to the amount of evaporated rain. The contribution of freezing/melting processes to the $Q_{1}$ budget is small, because the latent heat of fusion is nearly an order of magnitude smaller than the latent heat of evaporation. This result is consistent with our earlier work on GATE squall line simulation (Tao and Simpson, 1989b).

The eddy vertical heat and moisture convergence will only change their vertical profiles since the vertically integrated values are zero. Thus, absolute values are calculated in Table 1. The vertical eddy moisture flux is a major contributor to the model-derived $Q_{2}$ budget for both cases. This result is consistent with our earlier work on GATE squall and non-squall line simulations (Soong and Tao, 1980; Tao and Soong, 1986; Tao and Simpson, 1989b), with the results from the TAMEX squall line simulation (Tao et al, 1991) and with the results from the COPT-81 studies (Lafore et al, 1988; Chong and Hauser, 1990). In contrast, the contribution of vertical eddy heat convergence was only about 10 per cent of that due to latent heat release by condensation for the EMEX case and nearly 20 per cent for the PRESTORM case. This difference is a result of the stronger vertical velocities associated with the PRE-STORM case. Another difference between these two cases is that the warm-rain processes were dominant in the tropical-oceanic squall case. Also note that the vertical eddy moisture flux is a major contributor to the model-derived $Q_{2}$ budget in the stratiform region for the PRE-STORM case as conrasted with the EMEX case. This behavior is a result of the drier PRE-STORM environment.

Large-scale models (i.e., general circulation and climate models) require not only the global surface rainfall pattern but also the associated vertical distribution within the $Q_{1}$ and $Q_{2}$ budgets. The GCE model can help to identify which processes should be parameterized by the large-scale model (e.g., Table 1), as well as provide infornation on the vertical profiles of the $Q_{1}$ and $Q_{2}$ budgets. Figure 6 shows $Q_{1}$ and $Q_{2}$ profiles for the convective and stratiform regions for the EMEX and PRE-STORM squall cases. The GCE simulated $Q_{1}$ and $Q_{2}$ profiles at the mature stage of the PRE-STORM case are in good agreement with those determined diagnostically using rawinsonde data (Gallus and Johnson, 1991). Overall, the $Q_{1}$ and $Q_{2}$ profiles for the simulated EMEX case are characteristic of tropical regions, and similar to the diagnostic study of AMEX cloud clusters by Frank and McBride (1989). 
Table 1. The individual components of the heating budget for (a) the PRE-STORM and (b) the EMEX squall lines, averaged over a $16 \mathrm{~h}$ simulation time and normalized with respect to their surface rainfall. See text for more information.

TABLE 1(a)

(PRE-STORM Squall Line)

Total Convective Stratiform Non-Raining

\begin{tabular}{lllll}
\hline$<\bar{\rho} \mathrm{C}>$ & 1.47 & 1.13 & 0.27 & 0.07 \\
$<\bar{\rho} \mathrm{E}>$ & 0.69 & 0.24 & 0.36 & 0.09 \\
$<\bar{\rho} \mathrm{D}>$ & 0.74 & 0.22 & 0.33 & 0.19 \\
$<\bar{\rho} \mathrm{S}>$ & 0.47 & 0.07 & 0.18 & 0.22 \\
$<\bar{\rho}(\mathrm{C}-\mathrm{E}+\mathrm{D}-\mathrm{S})>$ & 1.05 & 1.04 & 0.06 & -.05 \\
$<\bar{\rho} \mathrm{m}\rangle$ & 0.12 & 0.05 & 0.07 & 0.00 \\
$<\bar{\rho} \mathrm{f}>$ & 0.09 & 0.06 & 0.03 & 0.00 \\
$\left\langle\frac{\partial \bar{\rho} \omega^{\prime} \theta^{\prime}}{\partial z}\right\rangle^{1}$ & 0.29 & 0.24 & 0.18 & 0.07 \\
$\left\langle\frac{L_{v}}{C_{p}} \frac{\partial \bar{\rho} \omega^{\prime} q_{v}^{\prime}}{\partial z}\right\rangle^{1}$ & 0.95 & 0.92 & 0.78 & 0.17 \\
$\left\langle\bar{\rho} \mathrm{Q}_{\mathrm{R}}>\right.$ & -.23 & -.00 & -.00 & -.05 \\
\hline
\end{tabular}

TABLE 1(b)

(EMEX9 Squall Line)

Total Convective Stratiform Non-Raining

\begin{tabular}{lllll}
\hline$<\bar{\rho} \mathrm{C}>$ & 1.77 & 0.91 & 0.81 & 0.05 \\
$<\bar{\rho} \mathrm{E}>$ & 0.96 & 0.18 & 0.73 & 0.05 \\
$<\bar{\rho} \mathrm{D}>$ & 0.29 & 0.03 & 0.26 & 0.00 \\
$<\bar{\rho} \mathrm{S}>$ & 0.02 & 0.00 & 0.01 & 0.00 \\
$<\bar{\rho}(\mathrm{C}-\mathrm{E}+\mathrm{D}-\mathrm{S})>$ & 1.08 & 0.76 & 0.33 & 0.00 \\
$<\bar{\rho} \mathrm{m}>$ & 0.07 & 0.01 & 0.06 & 0.00 \\
$<\bar{\rho} \mathrm{f}>$ & 0.04 & 0.01 & 0.03 & 0.00 \\
$<\frac{\partial \bar{\rho} w^{\prime} \theta^{\prime}}{\partial z}>^{1}$ & 0.16 & 0.08 & 0.11 & 0.01 \\
$\left.<\frac{L_{v}}{C_{p}} \frac{\partial \bar{\partial} \omega^{\prime} q_{v}^{\prime}}{\partial z}\right\rangle^{1}$ & 0.64 & 0.62 & 0.24 & 0.02 \\
$<\bar{\rho} \mathrm{Q}_{\mathrm{R}}>$ & -.28 & -.01 & -.05 & -.02 \\
\hline
\end{tabular}

$\left\langle x>=\int_{x} \int_{S c}^{27 o p} \int_{16 k}(x) \Delta \Delta \Delta z \Delta x\right.$

${ }^{1}$ These vertical eddy heat and moisture convergence are absolute values.

All numbers are normalized with respect to their corresponding surface rainfall rate $(\mathrm{Po})$ 

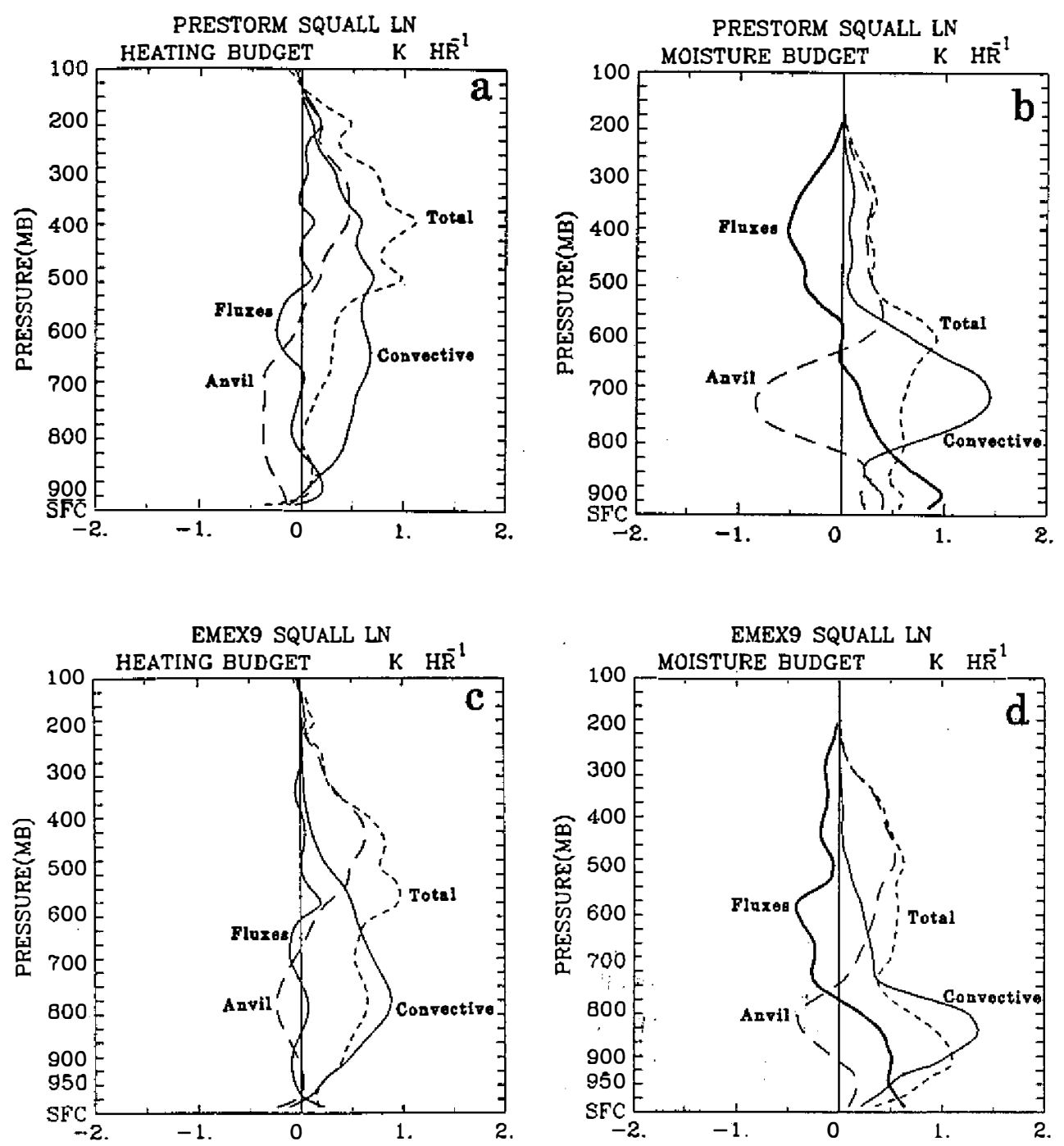

Fig. 6. (a) The heating and (b) the moisture budgets for the PRE-STORM squall line averaged over a $16 \mathrm{~h}$ simulation time. The contributions by the convective region, the anvil region (stratiform and non-raining areas), and the total vertical eddy flux convergence (calculated over the convective and anvil regions) are also shown. The profiles for the convective and anvil regions also include the individual contributions due to vertical eddy flux convergence. Figs. 6(c)-(d) are the same as (a)-(b), except for the EMEX case. The vertical eddy flux convergence term includes both cloud scale and sub-grid scale (turbulence) effects. 
Examination of Figure 6 suggests that there are many common features in the $Q_{1}$ profiles between the squall lines, even though these systems occurred in very different geographic locations. For example, the convective heating is at a maximum in the lower and middle troposphere, and is largely due to net condensation in the convective updrafts. In contrast, the stratiform (anvil) heating is maximized in the upper troposphere, where it is dominated by ice deposition and cloud water condensation. Cooling is also taking place in the stratiform region beneath the melting layer predominately as a result of rain evaporation, although melting within a kilometer below the $0^{\circ} \mathrm{C}$ level is also important. These features are well-known for mesoscale convective systems occurring in GATE, WMONEX, TAMEX, COPT-81 and PRE-STORM. The convective drying and stratiform moistening tend to offset each other in the low levels in the $Q_{2}$ profiles for the PRE-STORM case. The mid-level minimum in the $Q_{2}$ profile for the EMEX case was due to vertical eddy transport in the convective region. The contribution to the total $Q_{1}$ budget by cloud-scale fluxes is minor for the EMEX case. In the PRE-STORM case, the total vertical eddy heat flux is quite important in the boundary layer and again in the middle troposphere. An even more significant contribution by vertical eddy transport to the $Q_{1}$ budget was found for a mid latitude supercell case (Schlesinger, 1990).

\subsection{Cloud-Radiation Interaction}

Long-wave radiation affects the cloud structure in three different ways: (1) cloudtop cooling and cloud-base warming modify the thermal stratification of the clouds (Cox and Griffith, 1979), (2) differential cooling between clear and cloudy regions (Gray and Jacobsen, 1977), and (3) destabilization of the large-scale environment by radiative cooling. Recent numerical studies (Chen and Cotton, 1988; Dudhia, 1989; Tao et al, 1991) clearly indicate that the circulation in the stratiform region, as well as the amount of total surface precipitation, can be enhanced by long-wave radiative transfer processes. Yet, no details on the interaction between convective and stratiform regions (such as the transport of condensate rearward from the convective cells), as well as quantitative estimates of the effects of radiative cooling upon the amount of stratiform precipitation have been presented in any of these modeling studies. The same cases, a tropical oceanic (EMEX) and a mid latitude continental squall lines (PRESTORM) as discussed in the previous subsection, have been selected to assess the impact of long-wave radiative cooling on cloud development. For each case, a pair of experiments (one including long-wave radiative transfer processes and one without it) have been performed (Tao et al., 1993).

The GCE model results indicate that long wave radiative cooling enhanced the total surface precipitation for the PRE-STORM and EMEX cases by about $14 \%$ and $31 \%$ over a $16 \mathrm{~h}$ simulation time, respectively (Table 2 ). A rapidly developing and broader extent to the stratiform cloud layer were simulated for the tropical case. This feature is typical of the AMEX MCS (Frank and McBride, 1989). The cooling of the cloud top and warming of the cloud base by the long wave radiation can have the most impact on a well-developed stratiform cloud, which usually occurs at the mature stage of the squall system. Thus, the radiative cooling had the largest effect on the EMEX case. Also note that both convective and stratiform precipitation increase when the long wave radiative ransfer processes are included. This is because the clear air around the clouds cools more than the cloudy region due to long wave radiative cooling. The differential cooling between cloudy and clear regions can induce weak low-level convergence into the cloudy region and can enhance cloud activity as a whole. All of these processes are functioning in both squall cases. 
Table 2. Surface rainfall accumulated over the $16 \mathrm{~h}$ simulations with long wave radiation, and normalized with respect to the total model domain $\left(P_{o}\right.$ in $\mathrm{mm} /$ grid/16h). $\left(\Delta P_{c}, \Delta P_{s}\right)$ are the increases in surface rainfall (mm/grid/16 h) over the convective and stratiform regions, respectively, for the experiments with and without long wave radiative cooling. $\Delta P_{o}$ is the percentage of increase of the total surface rainfall for the experiments with and without long wave radiative cooling. $\Delta P_{o}$ is estimated with respect to the surface rainfall for the cases with long wave radiative cooling.

\begin{tabular}{lcccc} 
& $\begin{array}{c}\text { Total-Rain } \\
(\mathrm{mm} / \mathrm{grid} / 16 \mathrm{~h})\end{array}$ & $\begin{array}{c}\text { Stratiform } \\
\text { Portion }\end{array}$ & $\begin{array}{c}\left(\Delta P_{c}, \Delta P_{s}\right) \\
(\mathrm{mm} / \mathrm{grid} / 16 \mathrm{~h})\end{array}$ & $\begin{array}{c}\Delta P_{o}^{2} \\
(\%)\end{array}$ \\
\hline EMEX9 & 19.0 & $42 \%$ & $(3.3,2.6)$ & 31 \\
PreSTORM & 18.0 & $19 \%$ & $(1.9,0.8)$ & 14 \\
\hline
\end{tabular}

${ }^{1}\left(\Delta P_{c}, \Delta P_{s}\right)$ are the increments of surface precipitation over the convective and stratiform regions, respectively.

${ }^{2} \Delta P_{o}$ is the percentage increment for the total surface precipitation between the experiments with and without longwave radiative cooling.

\subsection{Convective and Stratiform Interaction}

Another important question that has been studied in the past decade is: what are the origins and growth mechanisms of particles in stratiform precipitation? For example, Chen and Zipser (1982) suggested that both depositional growth associated with upward motion in the anvil and the horizontal flux of hydrometeors from the convective region are important in the maintenance of anvil precipitation. In a kinematic model study of a GATE squall line, Gamache and Houze (1983) showed quantitatively that $25-40$ per cent of the stratiform condensate was created by mesoscale ascent at mid-to-upper levels in the stratiform region itself. Gallus and Johnson (1991) found that the contribution to surface rainfall from condensation in the mesoscale updraft was comparable in magnitude to the transport of condensate rearward from the convective line during a rapidly weakening stage of a mid latitude squall line. Using a kinematic (steady-state) cloud model, Rutledge (1986) suggested that the condensate produced by mesoscale ascent is largely responsible for the large horizontal extent of light stratiform precipitation to the rear of the same GATE squall line analyzed by Gamache and Houze (1983). Using higher resolution, Doppler-derived air motions associated with a mid latitude squall line as input in their two-dimensional kinematic model, Rutledge and Houze (1987) found that deposition in the mesoscale updraft accounted for 80 per cent of the stratiform precipitation. They also conducted a series of sensitivity tests and found that almost no rain reached the surface in the stratiform region without the influx of hydrometeors from the convective cells, while only about one-fourth as much stratiform rain reached the surface in the absence of mesoscale ascent.

In order to understand the interaction between convective and stratiform regions, it is necessary to estimate the horizontal transfer of hydrometeors between the two regions 
by calculating their water budgets (Gamache and Houze, 1983). The model results can be used to quantitatively study the interaction between convective and stratiform regions. By adding predictive equations for cloud water $\left(q_{c}\right)$, rain $\left(q_{r}\right)$, cloud ice $\left(q_{i}\right)$, snow $\left(q_{s}\right)$ and graupel/hail $\left(q_{g}\right)$ in the GCE model (Equations 10 to 14 shown in Part I), the total hydrometeor equation becomes:

$$
\bar{\rho} \frac{\partial q_{t}}{\partial t}=-\frac{\partial}{\partial x} \bar{\rho} u q_{t}-\frac{\partial}{\partial z} \bar{\rho} w q_{t}+\frac{\partial}{\partial z} \sum_{i}^{3} \bar{\rho} V_{i} q_{i}+\rho(c-e+d-s)
$$

where $q_{t}=q_{c}+q_{r}+q_{i}+q_{s}+q_{g}, e=e_{c}+e_{r}, d=d_{i}+d_{s}+d_{g}, s=s_{i}+s_{s}+s_{g}$, and $\mathrm{V}_{i} q_{i}$ stands for $\mathrm{V}_{r} q_{r}, \mathrm{~V}_{s} q_{s}$ and $\mathrm{V}_{g} q_{g}$. Vertical integration of (5) gives:

$$
\int_{s f c}^{Z_{T}} \bar{\rho} \frac{\partial q_{t}}{\partial t} \Delta z=\int_{s f c}^{Z_{T}}-\frac{\partial}{\partial x} \bar{\rho} u q_{t} \Delta z-P_{o}+\int_{s f c}^{Z_{T}} \rho(c-e+d-s) \Delta z
$$

where $P_{o}$ is the surface precipitation rate in $\mathrm{mm} \mathrm{h}^{-1}$. Equation (6) can be further integrated horizontally over the convective, stratiform and non-raining regions, respectively, to yield:

$$
\begin{aligned}
& <\bar{\rho} \frac{\partial q_{t}}{\partial t}>\operatorname{Con} v=<-\frac{\partial}{\partial x} \bar{\rho} u q_{t}>\operatorname{Conv}-P_{c}+<\rho(c-e+d-s)>\operatorname{Conv} \\
& <\bar{\rho} \frac{\partial q_{t}}{\partial t}>\operatorname{Str} f=<-\frac{\partial}{\partial x} \bar{\rho} u q_{t}>\operatorname{Str} f-P_{s}+<\rho(c-e+d-s)>\operatorname{Str} f \\
& <\bar{\rho} \frac{\partial q_{t}}{\partial t}>N s p=<-\frac{\partial}{\partial x} \bar{\rho} u q_{t}>N s p+<\rho(c-e+d-s)>N s p
\end{aligned}
$$

where $<>=\int_{x}\left(\int_{s f c}^{Z_{T}} \Delta Z\right) \Delta x, P_{c}$ and $P_{s}$ are the amounts of surface precipitation over the convective and stratiform regions, respectively. The first term on the right-hand-side of (7), (8) and (9) is the horizontal transfer term associated with the water budget. GCE model results can explicitly estimate each of the terms in (7), (8) and (9) over different time periods associated with various stages of the squall system's life cycle.

The water budgets in the convective, stratiform and non-raining regions associated with these two squall systems are shown in Figure 7. The water budgets are separated into three different layers: lower (surface to the $10^{\circ} \mathrm{C}$ level), middle (from $10^{\circ} \mathrm{C}$ to $-10^{\circ} \mathrm{C}$ ) and upper (above $-10^{\circ} \mathrm{C}$ ). The horizontal transfer of hydrometeors from the convective to the stratiform regions occurs mainly in the middle troposphere for the EMEX case. In contrast, in the 

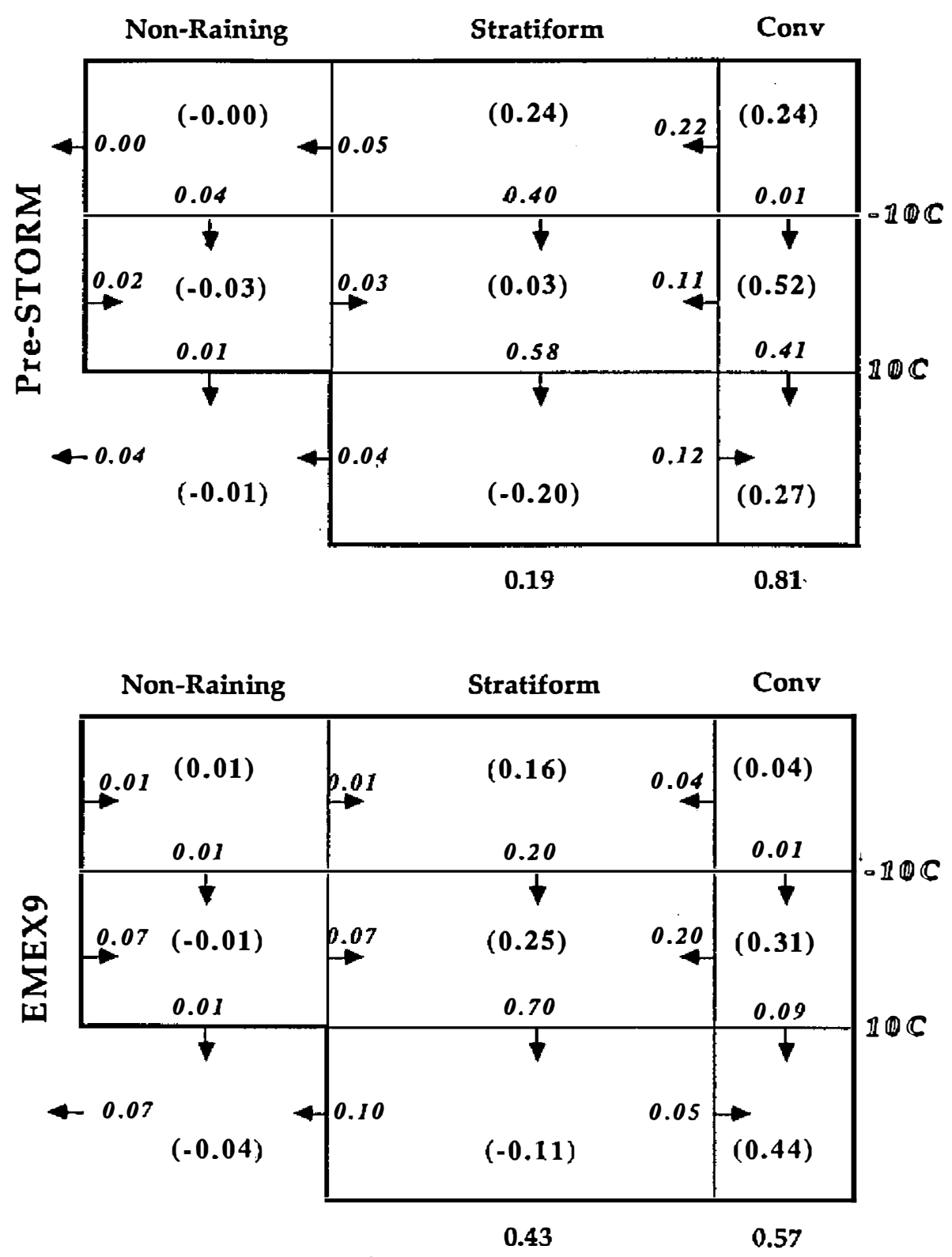

Fig. 7. The water budgets for the (a) PRE-STORM and the (c) EMEX squall simulations with long wave radiative cooling calculated over the $16 \mathrm{~h}$ model integration times. Italic numbers indicate the amount of condensate transferred between various regions and layers, while quantities in parentheses are the net condensation generated through microphysical processes. All of the numbers are normalized with respect to their corresponding total surface rainfall $\left(P_{o}\right.$ in Table 2$)$. 
PRE-STORM case two thirds of the horizontal transfer of hydrometeors is accomplished in the upper troposphere. The PRE-STORM case also experiences a more vigorous transfer of hydrometeors in the lower troposphere from the stratiform region back into the convective region. This is a consequence of the strong rear inflow simulated for this mid latitude squall. A downward transfer of hydrometeors from the middle to the lower troposphere is a dominant process in the stratiform regions for both cases. The interaction between the stratiform and non-raining region is less significant than that between the convective and stratiform regions.

The contribution to stratiform rain by the convective region can be estimated quantitatively by evaluating the ratio $\mathrm{R}=\mathrm{C}_{T} /\left(\mathrm{C}_{T}+\mathrm{C}_{m}\right)$, where $C_{T}$ is the horizontal transfer of hydrometeors from the convective region into the stratiform region above the $10^{\circ} \mathrm{C}$ level, and $C_{m}$ is the sum of the net condensation in the stratiform region and in the non-raining region above the $10^{\circ} \mathrm{C}$ level (Table 3). A small ratio indicates that the horizontal transfer of hydrometeors from the convective region is a small source of condensate for the stratiform anvil, whereas a ratio near unity indicates that nearly all of the condensate in the stratiform region was transported from the convective region. The ratio associated with the PRE-STORM case over the $16 \mathrm{~h}$ simulation is 0.56 . By contrast, the EMEX case has more stratiform rainfall than its PRE-STORM counterpart, and interestingly, the ratio is only 0.37 . Both ratios imply an important role for the convective region in the generation of stratiform rainfall. The relative importance of the horizontal transfer processes to the stratiform water budget is similar between the initial and the mature stages of the EMEX system, and this is probably due to the fact that stratiforn clouds developed rapidly in runs both with and without long-wave radiation. In contrast, during the initial stage of the PRE-STORM simulation, nearly all of the condensate in the stratiform region was a result of the horizontal transport from the convective region. As the PRE-STORM system matured, the contribution made by the horizontal transport of hydrometeors from the convective region (i.e., the ratio R) decreased, such that the sources of condensate in the stratiform water budget were similar for both mature storms. It is hypothesized that during the initial stage of the PRE-STORM simulation, much of the condensate transported from the convective region is used to moisten and modify the dry environment at middle and upper levels. Condensation and deposition in the stratiform water budget become increasingly more important with time once the largerscale environment reaches saturation. This evolution in the stratiform water budget is less obvious in the EMEX case because the environment is much more moist.

In Table 4, the ratios in Table 3 are compared against those determined from observational studies of composite wind and thermodynamic fields for five different GATE MCSs (Leary and Houze, 1980; Gamache and Houze, 1983), a mid latitude squall line (Gallus and Johnson, 1991), and a tropical-continental squall line (Chong and Hauser, 1989). For six out of the seven observed cases the ratio is very close to or above 0.50 . This implies that the convective region plays a very important role in the generation of stratiform rain. Very good agreement is evident between the ratio at the mature stage of the modeled PRE-STORM squall system and that estimated by Gallus and Johnson (1991). The modeled EMEX case indicates that a relatively small contribution $(0.37)$ to stratiform formation can be attributed to the horizontal transfer of condensate from the convective region. Stratiform cloud formation occurs earlier due to the very moist environmental conditions at the middle and upper levels associated with the EMEX case. Nevertheless, a direct comparison between these studies and the current model study should be done with caution, because a different spatial resolution and a different definition for the convective-stratiform region were used. The comparison between the simulated PRE-STORM and EMEX cases, however, is consistent because the same type of data set and the same criteria for partitioning the convective and stratiform regions are used. 
Table 3. Values of the ratio $\mathbf{R}$ for the entire model simulations with and without long wave radiation, as well as for the $4 \mathrm{~h}$ periods corresponding to the initial and mature stages in the runs with long wave cooling. See text for the definition of $\mathbf{R}$.

\begin{tabular}{lcccc}
\multicolumn{5}{c}{ (Ratio $\left.^{1}\right)$} \\
\hline & $\begin{array}{c}\text { Radiation } \\
(16 \mathrm{~h})\end{array}$ & $\begin{array}{c}\text { I-Stage } \\
(4 \mathrm{~h})\end{array}$ & $\begin{array}{c}\text { M-Stage } \\
(4 \mathrm{~h})\end{array}$ & $\begin{array}{c}\text { No-Rad } \\
(16 \mathrm{~h})\end{array}$ \\
\hline EMEX9 & 0.37 & 0.32 & 0.30 & 0.40 \\
PreSTORM & 0.56 & 0.98 & 0.38 & 0.66 \\
\hline
\end{tabular}

$I_{\text {Ratio }}=\left[C_{T} /\left(C_{T}+C_{m}\right)\right.$, where $C_{T}$ is the horizontal transfer of hydrometeors from the convective region into the stratiform region above the $10^{\circ} \mathrm{C}$ level and $\mathrm{C}_{\mathrm{m}}$ is the sum of the net condensation in the stratiform region and in the non-surface-raining region above the $10^{\circ} \mathrm{C}$ level.]

Table 4. The same ratio defined in Table 3, except for MCS cases A, B and C of Leary and Houze (1980), cases I and II of Gamache and Houze (1983), the 10-11 June squall line of Gallus and Johnson (1991), and the COPT squall line of Chong and Hauser (1989).

\begin{tabular}{lll} 
CASE & $\begin{array}{c}\text { Stratiform Portion } \\
(\%)\end{array}$ & Ratio \\
\hline LH-A & 0.40 & 1.00 \\
LH-B & 0.40 & 1.00 \\
LH-C & 0.40 & 0.50 \\
& & \\
GH-I & 0.49 & 0.55 \\
GH-2 & 0.49 & 0.64 \\
GJ-June10 & 0.30 & 0.37 \\
COPT 81 & 0.40 & 0.47 \\
\hline
\end{tabular}

\subsection{Momentum Transport Associated with Mesoscale Convective Systems in Various Geographic Locations}

The importance of the vertical transport of horizontal momentum by clouds in largescale dynamics was pointed out by Schneider and Lindzen (1976) and Stevens et al. (1977). The process of cumulus transport of horizontal momentum is complicated by the convectivescale pressure gradient force. This pressure gradient force can generate convective-scale 
horizontal momentum, which may be transported vertically by clouds. This process has been demonstrated by LeMone (1983) and LeMone et al (1984) using observational data, by Moncrieff (1992) using theoretic approach and by Tao (1983); Soong and Tao (1984) and Tao and Soong (1986) in numerical experiments. The results of several GCE model simulations are presented here.

The GCE model was applied to a case of a well-defined ITCZ rainband over the eastern tropical Atlantic ocean (GATE). The environmental wind shear associated with this rainband was characterized by weak shear in the direction normal to the rainband and a slightly stronger shear parallel to the rainband. It was found that the convective-scale pressure gradient is a dominant factor which affects the vertical transport of horizontal momentum in the direction nomal to the rainband. Different locations for the generation of new cells (in the upshear or downshear direction) produced either positive or negative momentum flux (Figure 8). When the model is initiated with a widespread random temperature perturbation (Tao and Soong, 1986) several cloud bands form at different times within the model domain. In this situation, cloud-cloud interactions are inevitable and commonly affect the location of new cell development. Therefore initialization was altered to generate a single cloud band within the domain (by confining the temperature perturbations to a very small area), in order to address the key question: "Is momentum transport predetermined under the influence of a specified environmental condition if an isolated cloud band is occurs within a large area?". In that series of experiments, it was found that the initial wind shear pre-detennined the location of new cell formation (Figures 8c and d). Both these situations occur in nature (Malkus and Riehl, 1964).

In the two-dimensional experiments, the convective-scale pressure gradient in the direction parallel to the rainband is neglected (Soong and Tao, 1984). Only the entrainment and detrainment can affect the v-momentum inside the simulated clouds. The convective-scale pressure gradient force on the vertical transport of v-momentum has been investigated by comparing results of the two- and three-dimensional experiments (Figure 9). The shape of the profiles of the v-momentum fluxes (total and in the updrafts) are similar for the two simulations. The model results also indicate that the v-momentum can be treated as a nearly conservative variable in the region of strong updrafts, i.e., when the vertical velocity exceeds $10 \mathrm{~m} \mathrm{~s}^{-1}$. However, for weaker updrafts, entrainment effects need to be considered. Our results also indicate that v-momentum transport by clouds can smooth out the tropical lowlevel easterly jet parallel to the rainband within half a day (if no counteracting processes are operating).

The equations representing the vertical transport of horizontal momentum by clouds in the Schneider and Lindzen (1976, referred to SL) scheme can be written as:

$$
\begin{aligned}
& \bar{\rho} \overline{w^{\prime} u^{\prime}}=M_{c}\left(u_{c}-\bar{u}\right) \\
& \bar{\rho} \overline{w^{\prime} v^{\prime}}=M_{c}\left(v_{c}-\bar{v}\right)
\end{aligned}
$$

where $M_{c}$ is the total cloud mass flux, $u_{c}$ and $v_{c}$ the flux weighted horizontal velocities inside clouds, and $u$ and $v$ the large-scale velocities. This scheme considers only the cloud updraft area and requires the knowledge of $M_{c}, u_{c}$ and $v_{c}$. The most frequently used hypothesis concerning these variables is that they are approximately conserved in the cloud updrafts. A comparison between model results and the SL scheme has been discussed in Soong and Tao (1984). The SL scheme produces both $u$ - and v-momentum flux profiles which are much larger than those simulated in the model for the upper troposphere. These larger values in SL can be attributed to their neglect of both dilution by entrainment and the convective-scale pressure gradient force. 

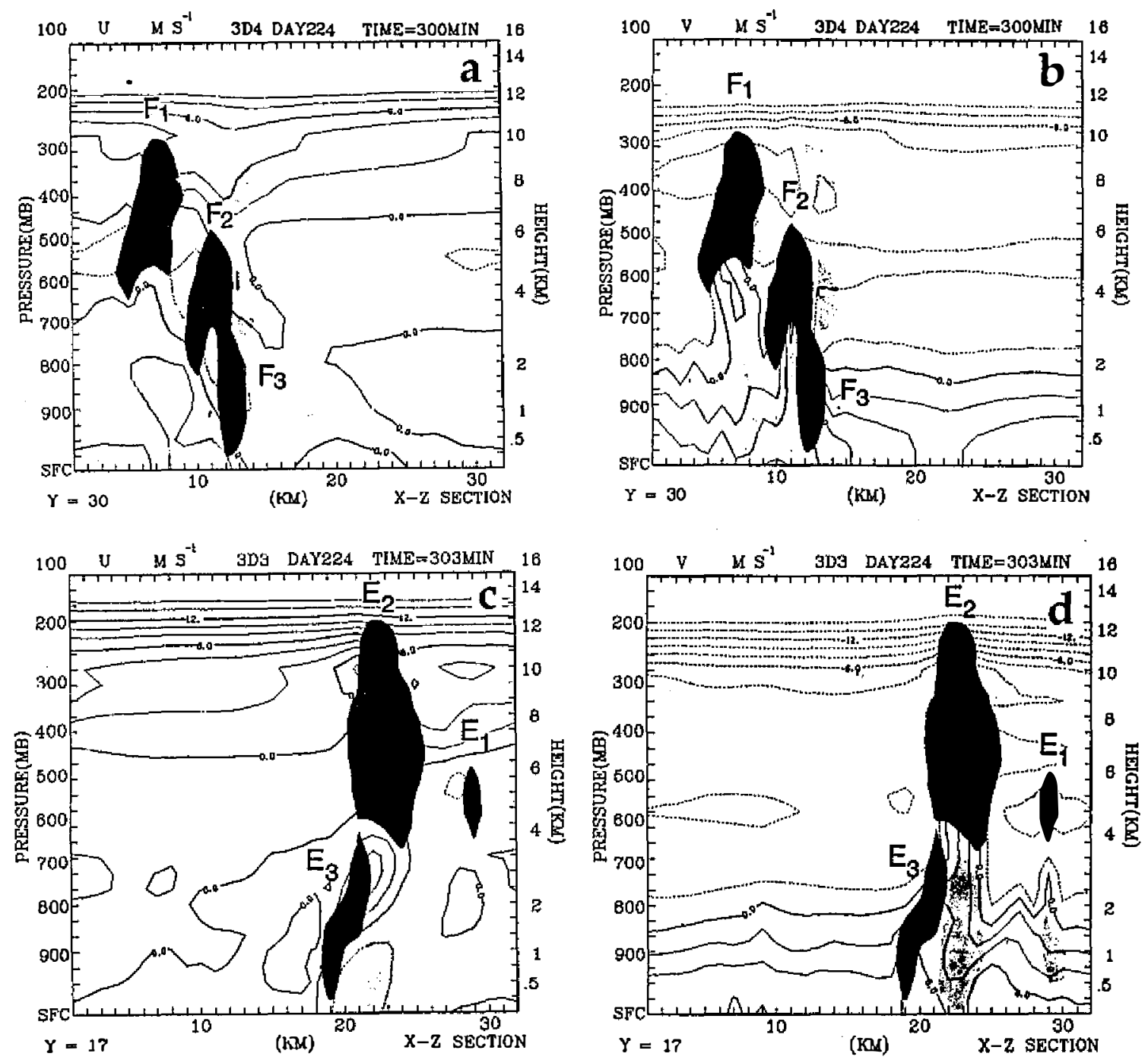

Fig. 8. The vertical cross sections perpendicular to the simulated cloud band. (a) u-momentum with contour interval of $2 \mathrm{~m} \mathrm{~s}^{-1}$. Vertical velocities greater than $0.5 \mathrm{~m} \mathrm{~s}^{-1}$ occur in the dark shaded region while those less than $-0.5 \mathrm{~m} \mathrm{~s}^{-1}$ occur in the light shaded region. (b) Same as (a) except for the v-momentum field. Figs. 8(c)-(d) are the same as (a)-(b), except for new convective cells developed on the opposite side. The w-u wind pattern in (a) can produce a negative vertical transport of u-momentum. By contrast, the w-u wind pattern can produce a positive vertical transport of u-momentum for case associated (c). 

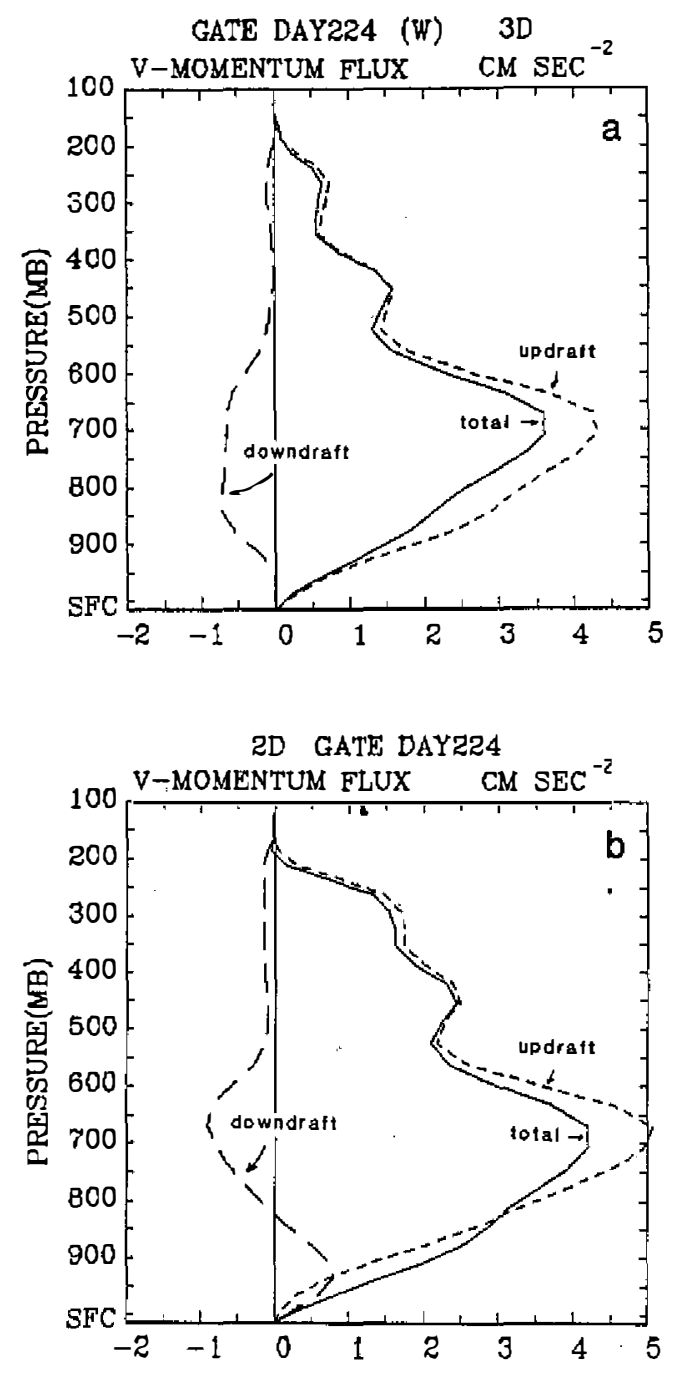

Fig. 9. The vertical transport of v-momentum predicted in (a) a three-dimensional and (b) two-dimensional experiments. The vertical momentum fluxes in the updrafts and downdrafts are represented by short and long dashed line, respectively.

In Tao and Soong (1986), the orientation of the simulated cloud band was aligned with the direction of the lower tropospheric wind shear. Observational studies in GATE indicate that convection inside a non-squall cluster usually forms along a line parallel to the wind shear. In general, most squall lines are oriented perpendicular to the wind shear. Tao et al. (1991) used a two-dimensional version of the GCE model to simulate a TAMEX squall line (Figure 10). The total u-momentum flux in the simulated TAMEX squall case is similar to 
the GATE fast-moving convective lines analyzed from aircraft data by LeMone et al. (1984). The total u-momentum fluxes are negative that is down the gradient. The GATE analyses peak at a higher altitude. The individual contributions from cloud updrafts and downdrafts are also shown in Figure 10, and they are almost always opposite in sign. The contribution from cloud downdrafts cannot be neglected. Also the negative u-momentum fluxes by downdrafts can be traced to the rear inflow originating from the midtroposphere (Tao et al., 1991). For the updraft region in the lower troposphere, the u-momentum flux is positive (against the gradient) and thereby not consistent with the well-known "mixing length" theory". The meso-high associated with the cold outflow can generate positive u-momentum (relative to the environment) near the leading edge of the simulated system. The v-momentum flux was much smaller than the u-momentum flux because of the small v-momentum shear. Also, by contrast, the v-momentum flux is qualitatively consistent with "mixing-length" expectations, since the perturbation pressure gradient force is included in the u-momentum equation, but not in the v-momentum equation. The important role of perturbation pressure on the vertical transport of horizontal momentum is again clearly identified.

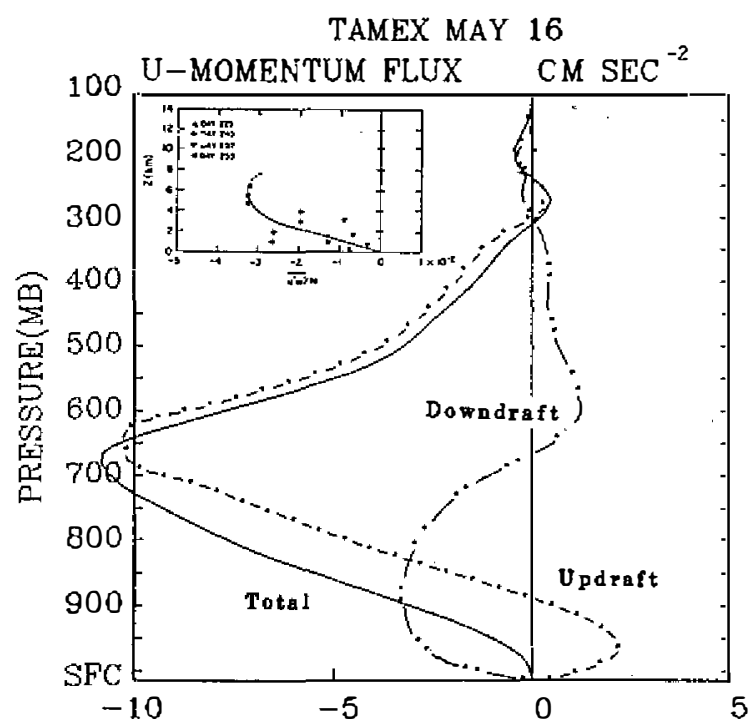

Fig. 10. The simulated u-momentum fluxes for a TAMEX squall line. Their contributions from cloud updraft and downdraft are also shown. The curves represented an average over the uniform grid model domain and $2 \mathrm{~h}$ of simulation time. Note that it needs to be divided by 7.5 to get correct values. The u-momentum fluxes from four GATE squall cases are also shown for comparison (From LeMone et al., 1984).

1 In mathematical form, the transport of a quantity $S$ using the "mixing-length" approach is given by $\overline{w^{\prime} s^{\prime}}=-K \frac{\partial \bar{s}}{\partial z}$, where $K$ is positive and the overbars and primes denote means and deviations from those means. 


\subsection{Cloud-Chemistry Study}

Organized mesoscale convection is an effective mechanism for the rapid removal of air from the boundary layer to the overlying free troposphere. The transport within convectivescale updrafts and downdrafts, and the mixing of cloud-free tropospheric air with cloudprocessed air can produce a post-stom trace chemical distribution that differs markedly from pre-storm values. The degree of vertical redistribution (or overtuming) is indicative of the intensity of the convection, and reflects the transport structure responsible for the mixing. The GCE model has been used to investigate the vertical transport and mixing of important trace species by mesoscale convection observed during the PRE-STORM, the NASA Amazon Boundary Layer Experiment (ABLE 2A and 2B), and the STEP/EMEX (see Table 7, Pickering et al., 1992c).

The GCE model generates consistent fields of wind, temperature, water vapor, and hydrometeors which comprise the cloud system. The model-derived wind fields can be used to calculate parcel trajectories through the simulated convective events. Sets of trajectories computed for several initial regions and grid points enable an interpretation of cloud-scale updrafts, downdrafts, and overall transport structure (Figure 11). The origins and character of the predicted flow patterns provide valuable insight into the mechanisms responsible for the redistribution of tropospheric trace constituents by deep convection.

Tropospheric concentrations of specific trace gases (e.g., $\mathrm{CO}, \mathrm{O}_{3}$ and $\left.\mathrm{NO}_{x}\right)$ were obtained for the specific convective environment from aircraft-derived instrumentation. The GCE model-generated wind fields were used to redistribute the initial concentrations of $C O$, $\mathrm{O}_{3}$ and $N \mathrm{O}_{x}$, which were assumed to act as conserved tracers during the period of convective mixing (Figure 12). Following the predicted redistribution, selected trace gas profiles are used in a series of one-dimensional photochemical model runs to estimate the rate of ozone production (or destruction) within the active cloud, and during the 24 hour period following the convective event. The details of inert passive tracer analysis and photochemical model application can be found in Scala et al (1990) and Pickering et al. (1992c), respectively. A recent observational study found that ozone mixing ratio was conserved during moist convection and can be used as a tracer for cloud entrainment studies (Pearson and Weaver, 1989).

Pickering et al (1992c) have shown that rapid vertical transport of air from urban plumes through deep convective clouds can cause marked enhancement of the rate of $\mathrm{O}_{3}$ production in the free troposphere (Table 5). For example, simulation of convective redistribution and the subsequent photo chemistry of an urban plume from a PRE-STORM case suggests enhancement of $\mathrm{O}_{3}$ production in the free tropospheric cloud outflow layer by a factor of almost four. In contrast, simulation of convective transport of an urban plume from the ABLE 2B case showed enhancement of $\mathrm{O}_{3}$ production by a factor of 35 . The different enhancements are a consequence of: (1) the intensity of cloud vertical motion, (2) the initial boundary layer $\mathrm{O}_{3}$ precursor concentrations, and (3) the initial amount of background free tropospheric $N O_{x}$.

\section{APPLICATIONS OF THE GODDARD CUMULUS ENSEMBLE MODEL FOR TRMM}

\subsection{Latent Heat Retrieved from Vertical Hydrometeor Distributions}

It is well-known that cumulus convection and its associated latent heat release are very important to the large-scale circulation. The latent heat release is the main source of energy to balance outgoing radiation and to drive atmospheric circulations. The vertical profile of 

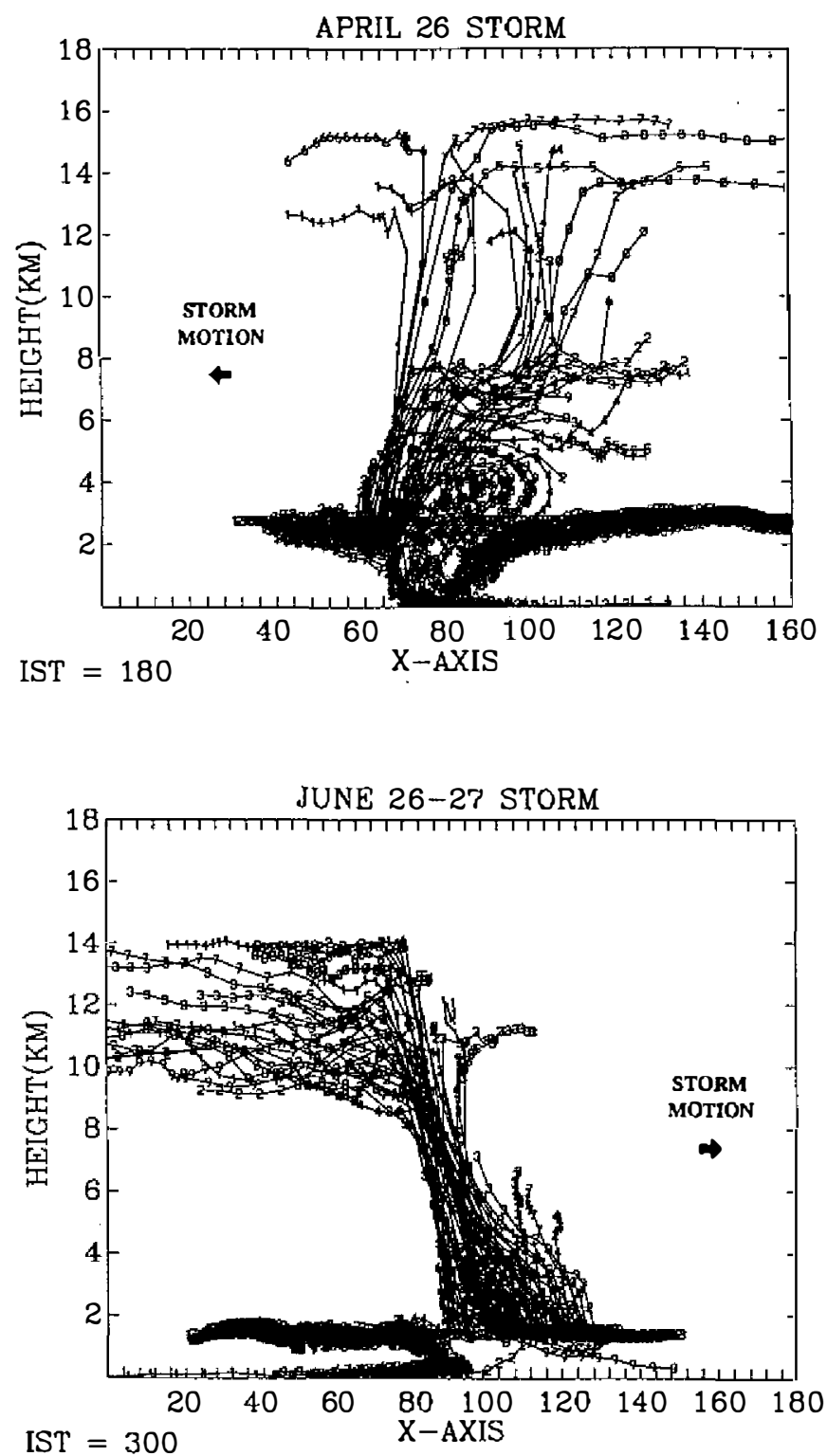

Fig. 11. Parcel trajectory calculated during the mature stage of two distinctly different squall-typeconvective systems. (a) April 26 squall line observed during ABLE 2B, (b) June 26-27 convective system observed during PRESTORM. 

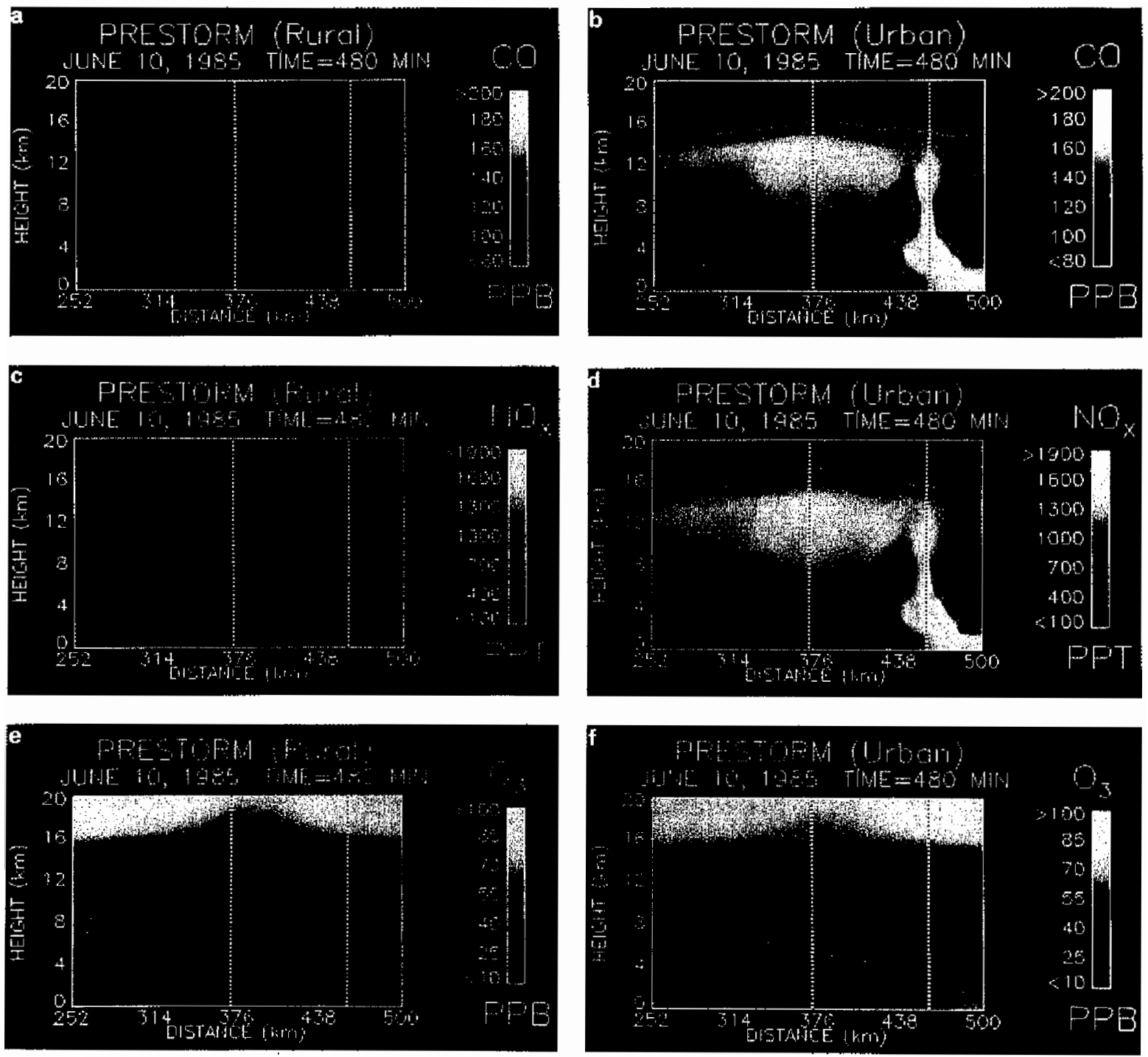

Fig. 12. CO, $N O_{x}$, and $O_{3}$ tracer analyses for June 10-11, 1985, Kansas/ Oklahoma PRE-STORM convective event. Dashed vertical lines indicate cloud-processed profiles used in photochemical simulations. (a), (c), (e) rural air; (b), (d), (f) urban air. Note that low $\mathrm{O}_{3}$ near the surface in the rural air propagates upward, decreasing concentrations in the updraft and anvil region (panel e). This effect is less pronounced in the urban plume, which began with $>60 \mathrm{ppbv} \mathrm{O}_{3}$ in the boundary layer. 
Table 5. Summary of convective ozone production enhancement for six individual convective events that have been analyzed at Goddard.

\begin{tabular}{|c|c|c|}
\hline \multicolumn{3}{|c|}{$\begin{array}{l}\text { Define "Convective Enhancement Factor" } \\
\left.\mathrm{P}\left(\mathrm{O}_{3}\right)\right]^{24-h r} \text { post-storm } \text { Cloud-processed }=C E F\end{array}$} \\
\hline \multicolumn{3}{|c|}{$\mathrm{P}\left(\mathrm{O}_{3}\right)^{24-\mathrm{hr} \text { post-storm Undisturbed }}$} \\
\hline Study & Description & $\begin{array}{l}\text { Mid-Upper Trop. } \\
\text { Cloud Ontflow CEF }\end{array}$ \\
\hline 1 & $\begin{array}{l}\text { Okla. PRESTORM, } 15 \text { June } 85 \\
\text { Pickering et al. [1990] }\end{array}$ & 4 \\
\hline 2 & $\begin{array}{l}\text { ABLE 2A, } 3 \text { Aug. } 85 \\
\text { Pickering et al. [1991a] }\end{array}$ & $\mathrm{P}\left(\mathrm{O}_{3}\right):-\cdots+$ \\
\hline $2 a$ & $\begin{array}{l}\text { ABLE 2A Storm, Savanna Burning } \\
\text { Pickering et al. [1992a] }\end{array}$ & 53 \\
\hline $2 b$ & $\begin{array}{l}\text { ABLE 2A Storm, Forest Burning } \\
\text { Pickering et al. [1992a] }\end{array}$ & 59 \\
\hline 3 & $\begin{array}{l}\text { ABLE 2B, } 6 \text { May } 87 \\
\text { Scala et al.:[1990] }\end{array}$ & -1 \\
\hline 4 & $\begin{array}{l}\text { STEP/EMEX, } 2 \text { Feb. } 87 \\
\text { Pickering et al. [1991b] }\end{array}$ & $<1$ \\
\hline 5 & $\begin{array}{l}\text { ABLE 2B, 26 Apr. } 87 \\
\text { - Clean Air } \\
\text { - Urban Plume }\end{array}$ & $\begin{array}{l}2.5 \\
35\end{array}$ \\
\hline 6 & $\begin{array}{l}\text { Okla. PRESTORM, } 10 \text { June } 85 \\
\text { - Rural.Air } \\
\text { - Urban-Plume }\end{array}$ & $\begin{array}{l}2.5 \\
3.9\end{array}$ \\
\hline
\end{tabular}

the heat release is also important for atmospheric dynamics. For example, the 30-60 day oscillation in the tropics and its possible connection with the El Nino-Southern Oscillation is strongly affected by the shape and structure of the vertical heating profile (Lau and Peng, 1987). Trenberth et al. (1988) also indicated that the pattem of latent heat release in the tropics has made a significant impact on mid latitude climatic events such as the 1988 North American drought. All of these studies reemphasize the importance of obtaining information about the vertical structure of cloud latent heating. Thus, one of the major TRMM objectives is to advance our understanding of the global energy and water cycle by means of providing four-dimensional distributions of rainfall and inferred heating over the globe (Simpson, 1988).

The latent heat release is a consequence of phase change (vapor, liquid and solid) 
of water, and Tao et al. (1990) have developed algorithms to estimate the latent heating by cloud systems as a function of their vertical hydrometeor profiles. Few hydrometeor profiles are available prior to TRMM launch and the associated latent heat profiles are not directly measurable. Therefore our algorithm to obtain latent heating profiles from those of hydrometeors had to be both derived and tested using the GCE model. Figure 13 is a schematic flow chart illustrating the derivation and validation of the heating budget algorithm. First, an environmental condition associated with a specific cloud system is used as the initial condition for the GCE model. The model, in turn, can estimate the heating budget caused by microphysical processes as in (3). The GCE model also provides the profile of different hydrometeor types which correspond to the associated model-predicted heating budget. These hydrometeor profiles are used as the input for the proposed algorithm. One of the keys to deriving the algorithm is construction of the process diagrams associated with cloud microphysical processes (see Figure 4 in Tao and Simpson, 1993). Another key to the algorithm development is that convective (heavy precipitation) and stratiform (light precipitation) portions of the cloud system are separated.

The heating/hydrometeor algorithm consists of six terms. They are

$$
Q 1=R C o n d+C C o n d+D e p+D e p I+E v a p+M e l t .
$$

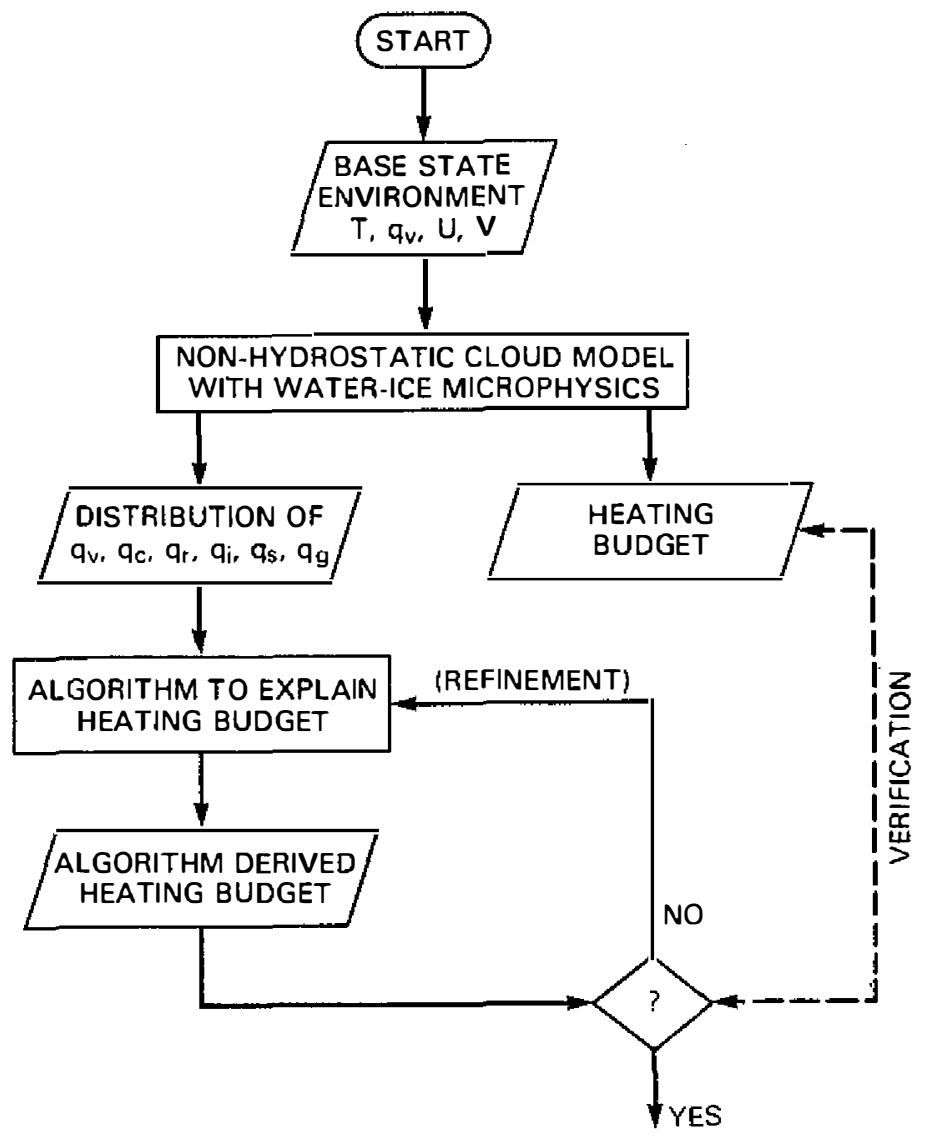

Fig. 13. Schematic diagram showing the procedure for deriving and validating the heating budget estimation algorithm. 
Formulations of each term can be found in Tao et al (1990). Mature stages of a GATE and a PRE-STORM squall-type convective system have been examined (Figure 14) and the algorithm-derived heating budget is in good agreement with the budget explicitly predicted by the cloud model. It should be noted that the algorithm-derived heating profiles in Figure 14 were calculated using GCE heating distributions that were averaged over the model domain $(512 \mathrm{~km})$ and throughout a two hour period during the mature stages of each storm. Heating algorithms were also devised using different spatial and temporal averaging of the simulated heating distributions. Preliminary results indicated that the heating diagnosed from the algorithms was insensitive to selected time and space scales, so long as the contributions to the total heating were partitioned between the convective and stratiforn rain regions. Recently, Willis and Heymsfield (1989) examined aircraft observations of particles and modeled the ice and liquid water contents above, within, and below the melting layer in the stratiform region associated with a mesoscale convective system during the PRE-STORM Experiment. They estimated a mean cooling rate of $0.22^{\circ} \mathrm{C} \mathrm{h}^{-1}$ in the melting layer which extends downward from the $0^{\circ} \mathrm{C}$ level. This result is consistent with the model-simulated and algorithm-derived cooling rates from melting shown in Figs. $14 \mathrm{~b}$ and $14 \mathrm{~d}$, respectively. Such verification of the algorithm-derived heating budget using indirect observational results is necessary for the verification of our algorithm.

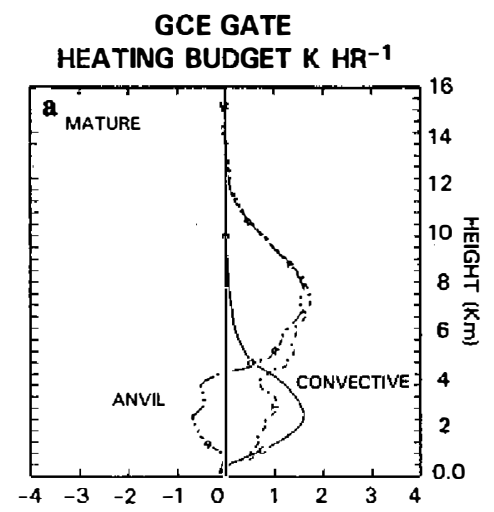

GCE PRESTORM
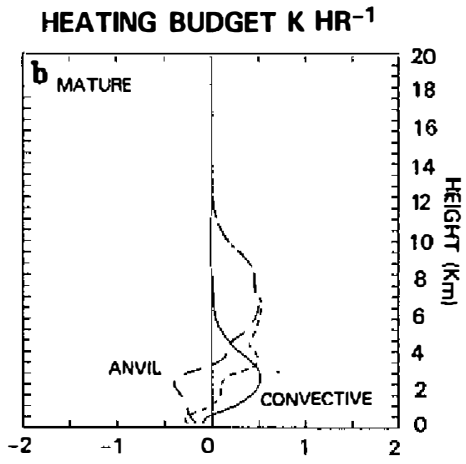

GATE ALGORITHM HEATING BUDGET K HR ${ }^{-1}$

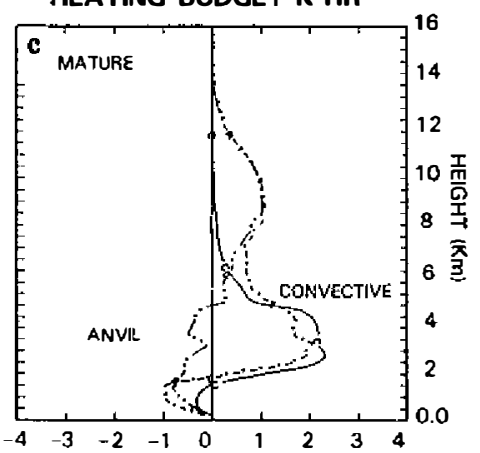

PRESTORM ALGORITHM HEATING BUDGET K $\mathrm{HR}^{-1}$

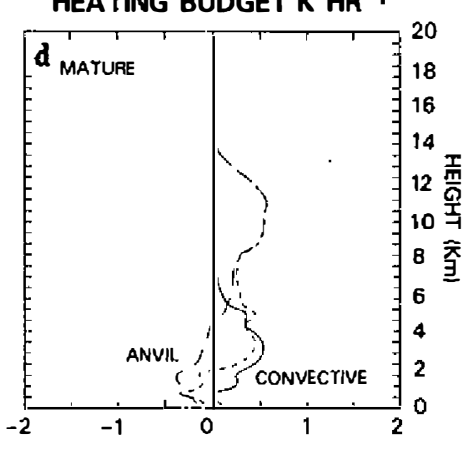

Fig. 14. GCE model simulated heating budget for (a) a tropical and (b) a mid latitude squall systems during its mature stage. (c) and (d) are the same as (a) and (b), respectively, except algorithm derived heating budget. Letters denote convective (C), anvil (A) and total (T). These curves represented an average spanning the entire GCE model domain over a 2 -h time period. 


\subsection{Rain Retrieval Algorithms Development}

\section{(a) Coupling the GCE model with Radiative Transfer Models to Develop and Test Rain Retrieval Algorithms}

The vertical structure of the cloud parameters (hydrometeors) is the driver in the radiative transfer calculations that determine upwelling radiance at the top of the atmosphere. The GCE model produces modeled vertical cloud structures which are supplied to a passive microwave radiative model for each microwave frequency of interest. One product is a relationship between rain rate and brightness temperature $\left(T_{B}\right)$, which can be used to retrieve rain rates from brightness temperatures sensed by air- or space-bome (e.g., TRMM) microwave instruments, and then tested by comparison with other rain rate observations, obtained for example by calibrated surface radars. Encouraging results have already been derived from this approach (Adler et al., 1991). Figure 15 shows the surface rain rate pattern simulated from the three-dimensional (3D) GCE model for a GATE squall convective line. The corresponding microwave $T_{B}{ }^{\prime}$ s associated with the four different frequencies $(10,19,37$ and $86 \mathrm{GHz})$ were calculated by the microwave radiative model (Figures $15 \mathrm{~b}-15 \mathrm{e}$ ). There is a strong rain signal in various microwave frequencies. Then, using the $\mathrm{T}_{B} / \mathrm{s}$-rainfall relationship derived from Figure 15, a regression formula was established for rain retrievals using satellite data with multifrequency microwave signatures. For example, the rain rate estimated from SSM/I data using the GCE model-based algorithm is in good agreement with ground-based radar measurement for a rain situation near the Wallops Island (Adler et ah, 1989).

Another product of this linkage with radiative models is increased understanding of how cloud hydrometeors interact with radiative processes under different conditions. For example, Adler et al. (1991) found that brightness temperatures at 19, 37 and $86 \mathrm{GHz}$ were significantly affected by ice in the GCE model convective system, although $10 \mathrm{GHz}$ results showed very little effect. They also found that the presence of non-precipitating cloud water associated with either very low rain rates or very high rain rates, together with significant ice, affected the brightness temperatures. These results illustrate the need to take into account the evolution of non-precipitating cloud water and precipitation-sized ice in the retrieval of rain from passive microwave space observations.

This GCE-microwave radiative model coupling also provides a new way of testing cloud microphysical models, compared with the existing methods using penetrative aircraft and the slanting beams from surface radars. Comparing the model-derived brighmess temperatures with those observed from multichannel microwave-equipped overflights permits a new, stringent test of vertically-integrated hydrometeor profiles, which also comprises a test of model dynamics and microphysics (Simpson et ah, 1988). Preliminary 3D GCE model results for a COHMEX case have been tested and the model-predicted cloud tops and overall structure of major convective cores are matched fairly well with the ground-based radar observations (Yeh et al., 1990). More detailed comparison between model results and observations as well. as sensitivity tests of models are underway. This GCE model-generated COHMEX storm structure has also been used to simulate TRMM radar reflectivities and rainfall algorithm development (Yeh et al., 1992).

\section{(b) Rain-Latent Heat-Retrieval Algorithms Using A Multichannel Statistical Approach}

A self-consistent iterative technique (Kummerow et al., 1989) has been developed to retrieve hydrometeor distributions from multichannel passive microwave observations. The technique relies on a large set of distinct cloud structures to simulate $\mathrm{T}_{B} \mathrm{~S}$. Consistency between observed and simulated $T_{B} S$ is then used to select the cloud structure that best fits 

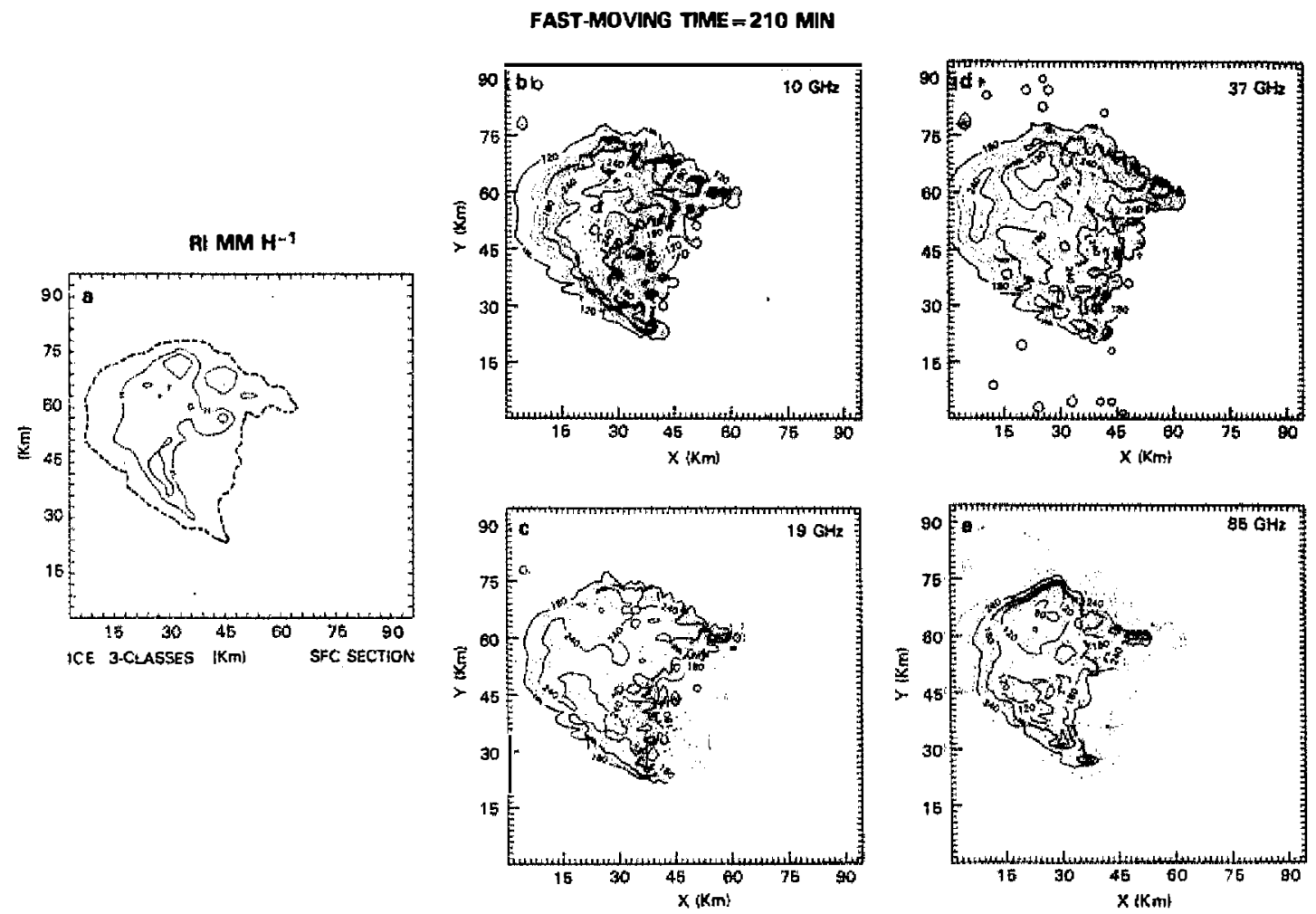

Fig. 15. (a) GCE model-predicted surface rainfall for a tropical squall line. Corresponding estimated upwelling brightness temperatures for (b) 10, (c) 19 , (d) 37 and (e) $85 \mathrm{GHz}$.

the rainfall scene in question. For each structure, radiative transfer calculations that account for multiple scattering through the Eddington approximation are used to calculate the $T_{B}{ }^{\prime} \mathrm{s}$ of different microwave frequencies. These are calculated over a wide range of surface rainfall rates, surface temperatures and emissivities, and vertically-integrated cloud (non precipitating) water contents. A set of linear regression coefficients relating each of these parameters as a function of $\mathrm{T}_{B}$ in each of the microwave channels is determined separately over different rain rate intervals using piece wise-linear statistics. A similar approach has been used by Mugnai et al. (1990) and Xiang and Smith (1992) except that the set of distinct cloud structures were derived from a convective-scale cloud model. Despite the simple representation of different cloud microphysical structures, Kummerow et al. (1989) have shown that the retrieved hydrometeor distributions agree quite well with coincident surface radar-derived rainfall rates.

The precipitation profiles as well as the surface rain rate derived from the multichannel passive microwave rain-retrieval algorithm can be used as the input for our heating profile retrieval algorithm (Tao et al., 1990, 1993). The latent heating algorithm has shown that the derived cooling by Evap (evaporative cooling) and Melt (cooling by melting of ice) are in particularly good agreement with those cooling rates calculated explicitly from the GCE 
model. However, empirical coefficients that relate the vertical distributions of cloud water condensation $(C C o n d)$ and cloud ice deposition $(D e p I)$ are adjusted iteratively to produce algorithm-derived heating rates that compare best with the model-calculated heating profiles. The vertically-integrated heating profiles are related to surface precipitation rates $\left(P_{0}\right)$ and surface heat fluxes $\left(S_{o}\right)$ by

$$
\int_{Z_{\text {Ba se }}}^{Z_{\text {top }}} \rho Q_{1} \Delta Z=S_{o}+\frac{\mathrm{L}_{v}}{C_{p}} P_{\circ}
$$

The surface heat fluxes are generally smaller than surface precipitation rate and can be neglected. The terms, $R C$ Cond and $D e p$, are included in (12) because the conversion processes from small non-precipitating particles to larger precipitating particles are quite important. Tests have been made and these two terms can be eliminated from the heating/hydrometeor algorithm if we adjust the coefficients associated with CCond and DepI as discussed above. The drawback of the elimination of $R C o n d$ and $D e p$ is that the derived heating profile may peak at higher elevation than those predicted. The empirical coefficients can be determined by

$$
\begin{array}{r}
\int_{Z_{B_{\text {ase }}}}^{Z_{\text {top }}} \rho Q_{1} \Delta Z-\int_{Z_{B_{\text {ase }}}}^{Z_{\text {iop }}} \rho(\text { Evap }+ \text { Melt }) \Delta Z \\
=\text { coef } \times \int_{Z_{B_{\text {a se }}}}^{Z_{\text {iop }}} \rho\left(\frac{L_{v}}{C_{p}} q_{c}+\frac{L_{s}}{C_{p}} q_{i}\right) \Delta Z
\end{array}
$$

We have tested our algorithm using the $P_{o}$ and vertical hydrometeor profiles associated with a West Pacific tropical typhoon. These were retrieved by Xiang and Smith (1992). Figure 16 shows their retrieved hydrometeor and our derived latent heating profiles for 10, 5 and $1 \mathrm{~mm} \mathrm{~h}^{-1}$ surface rainfall rates. The qualitative similarity in the shapes of the profiles is encouraging, with the corresponding two bulges in the free atmosphere and the lowestlevel cooling suggested by the decrease in liquid-water content below about $1 \mathrm{~km}$. Also, the derived heating profile is somewhat similar to those simulated by Lord et al. (1984), except a stronger cooling and much weaker melting are derived. More tests using the hydrometeor profiles associated with various types of convective systems derived by different method (e.g., Kunnerow et al., 1989) are underway.

\subsection{GCE Model Application for Climate Study}

Water vapor is the most abundant greenhouse gas in the atmosphere. The amount of water vapor in the global atmosphere is strongly affected by short-term hydrologic processes such as precipitation and vaporization. The long-term distribution of water vapor is a strong function of the underlying boundary conditions, for example sea surface and land surface temperature. The interaction of atmospheric hydrologic processes with the earth's surface is characterized by a quasi-equilibrium global scale distribution of water vapor. As a result, global warming deriving from an increased greenhouse effect is likely to be accompanied by changes in the global distribution of clouds, precipitation, and water vapor. It is clear that a better understanding of the climate feedback process rests on an improved knowledge of the interaction between radiation, atmospheric dynamics and global hydrologic processes, including the redistribution of clouds and water vapor. Global climate models, in which cumulus processes are parameterized, are too crude to provide reliable information on this 
interaction. For this purpose, a cloud ensemble model with explicit microphysics and cloudscale interaction and dynamics is highly desirable (Lau et al., 1993 and Sui et al., 1993a and $b$ ).

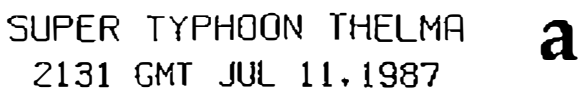

131 GMT JUL 11,1987

RAINFALL RETRIEVAL

DECONVOLVEO OATA
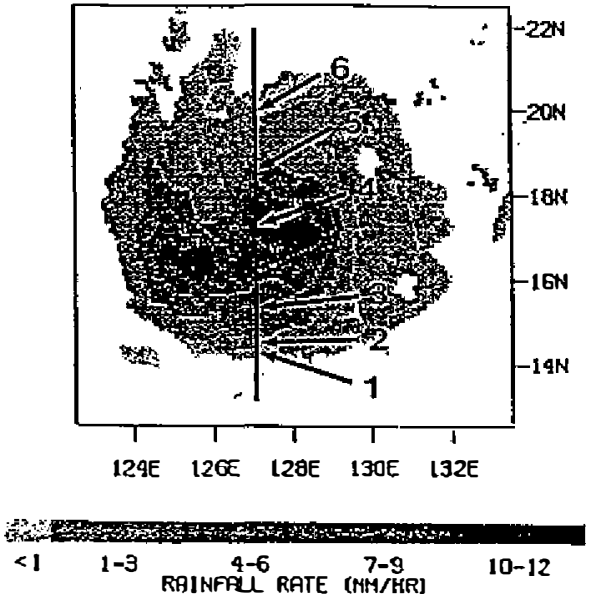

b

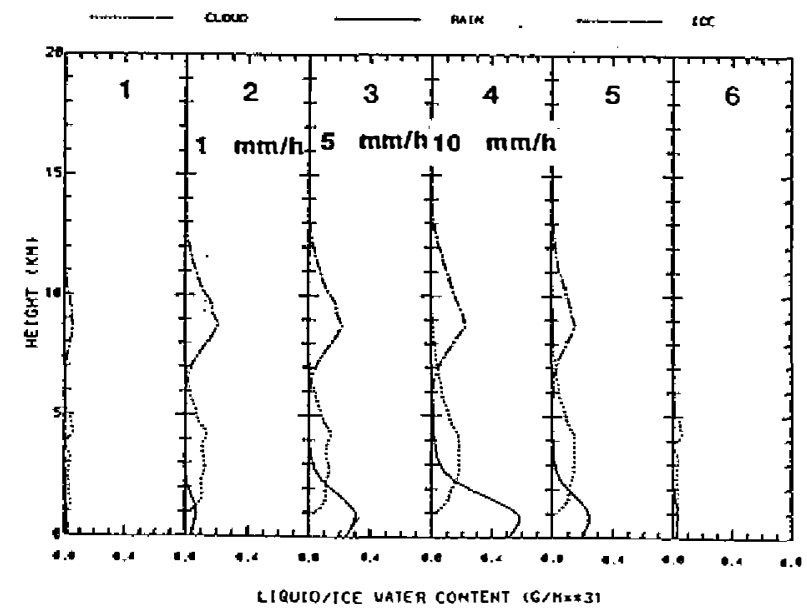

Fig. 16. (a) Rain rate distribution (in $\mathrm{mm} \mathrm{h}^{-1}$ ) for super Typhoon Thelma using the preliminary version of the hybrid retrieval algorithm. (b) Microphysical profiles at the six positions indicated along the cross section drawn through the storm core given in (a). (c) Algorithm derived heating profiles. (a) and (b) are from Xiang and Smith (1992). 

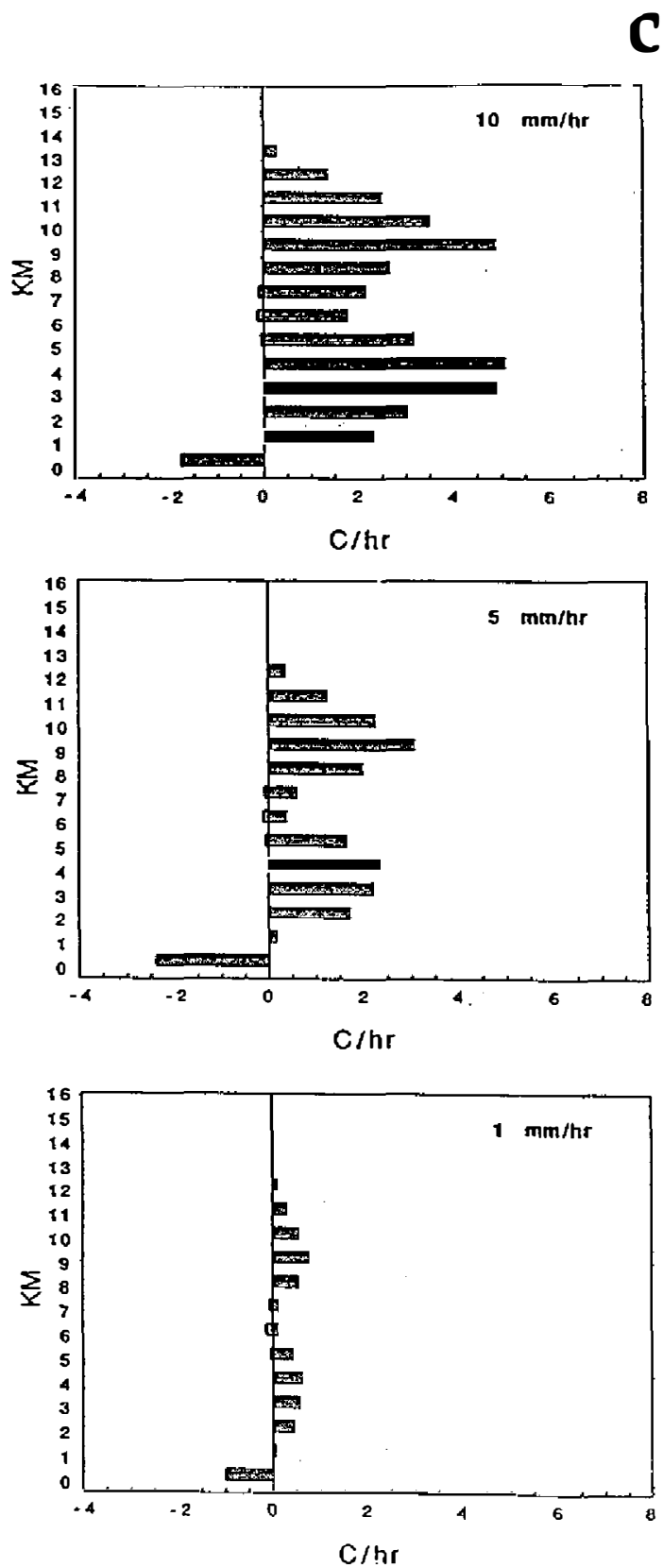

Fig. 16. (Continued.)

For climate applications, we need to obtain the long-term equilibrium response of tropical convection to surface warming. Lau et al. (1993) and Sui et al. (1993a and b) used initial conditions which consisted of temperature, moisture, and zonal wind profiles representative of deep convective events over the tropical western Pacific region, and a sea surface 
temperature of $28^{\circ} \mathrm{C}$ (referred to as the control case). The GCE model uses a stretched vertical coordinate with a resolution ranging from $220 \mathrm{~m}$ in the boundary layer to $1050 \mathrm{~m}$ in the topmost layer. The top of the model domain is set to $21.5 \mathrm{~km}$. The model uses constant $1.5 \mathrm{~km}$ horizontal resolution over a domain of $768 \mathrm{~km}$. Model integration was nun for 52 days with a $12 \mathrm{~s}$ time step. A second integration was performed with identical initial conditions but with the underlying sea surface temperature increased to $30^{\circ} \mathrm{C}$ (referred to as the warm case). Since the length of the time integration was much longer than the life cycle of the convective clusters (typically 6 to 24 hours), the results are independent of the initial conditions and equilibrium states are assured. Figure 17 shows the time series of equivalent potential temperature and moisture over the entire domain for the control and the warm case, in comparison. Two time scales are apparent in the time series. The first is the equilibration period which is about 20 days. The second is characterized by a short-term (approximately 1-3 day period), out-of-phase oscillation between temperature and moisture. The first time scale is determined by the interaction between cloud dynamics, latent heating and radiation. The second time scale is due to the role of precipitation as a sink for atmospheric moisture, and represents the mean ensemble recycling time of water by tropical convection. In the equilibrium state, the warm case has a mean tropospheric temperature about 2-3 degrees higher and 20 per cent more moisture than the control.

For the environment characterized by warmer sea surface temperatures, there are apparent changes in the vertical distribution of water vapor and clouds. The convection is significantly invigorated. More abundant higher-level clouds, and an increase in surface precipitation are evident. A surplus in water vapor is maximized near the surface, and decreases monotonically with height up to $10 \mathrm{~km}$ (Figure 18). In contrast, the percentage increase in water vapor increases with height reaching a maximum between 8 and $16 \mathrm{~km}$. While the relative humidity remains unchanged below the froezing level, it is increased in the middle and upper troposphere, where there is also a noticeable increase in cloud cover and cloud water content . The local precipitation gain as a result of the enhanced surface evaporation is large and primarily in the form of convective rain, indicating that the surface warming induces a large positive feedback between dynamic moisture convergence and precipitation. This also implies that there must be moisture transport from other areas to the region of warming. Our results on the sense of the water vapor feedback do not support hypothesis that upper tropospheric drying may accompany enhanced convection (see discussion in Lindzen, 1990a and b). On the contrary, the GCE model results indicate that when a warmer ocean leads to enhanced convection, water vapor increases throughout the troposphere and the percentage increase in the upper troposphere is substantial. This provides further evidence that the water vapor/climate feedback is largely positive (Betts, 1990; Arking, 1991, 1992).

\section{SUMMARY AND FUTURE WORK}

The Goddard Cumulus Ensemble (GCE) model, which is a multi-dimensional nonhydrostatic dynamic/microphysical cloud model, has been useful in simulating many different mesoscale convective systems that occurr in various geographic locations. Several specific applications of the GCE model to the study of cloud precipitating processes, such as cloud interactions and mergers, clouds and their feedback on the large-scale circulation, cloudradiation interaction, convective and stratiform interaction, horizontal momentum transport by cloud systems, and cloud-chemistry interaction, as well as to TRMM, have been described in this paper. 
The model and several of its applications, however, still need many further developments. The need to improve the cloud microphysical formulations, particularly ice processes, was noted in Part I, as were the steps underway to accomplish this goal. In addition, the cloud-radiation and convective-stratiform interactions discussed in Sections 3.3 and 3.4 are only a first step in an effort to quantitatively estimate how cloud and long wave radiative transfer processes interact with each other. We contrasted two squall systems which developed under a relatively dry (PRE-STORM) and a moist (EMEX) marine environment.
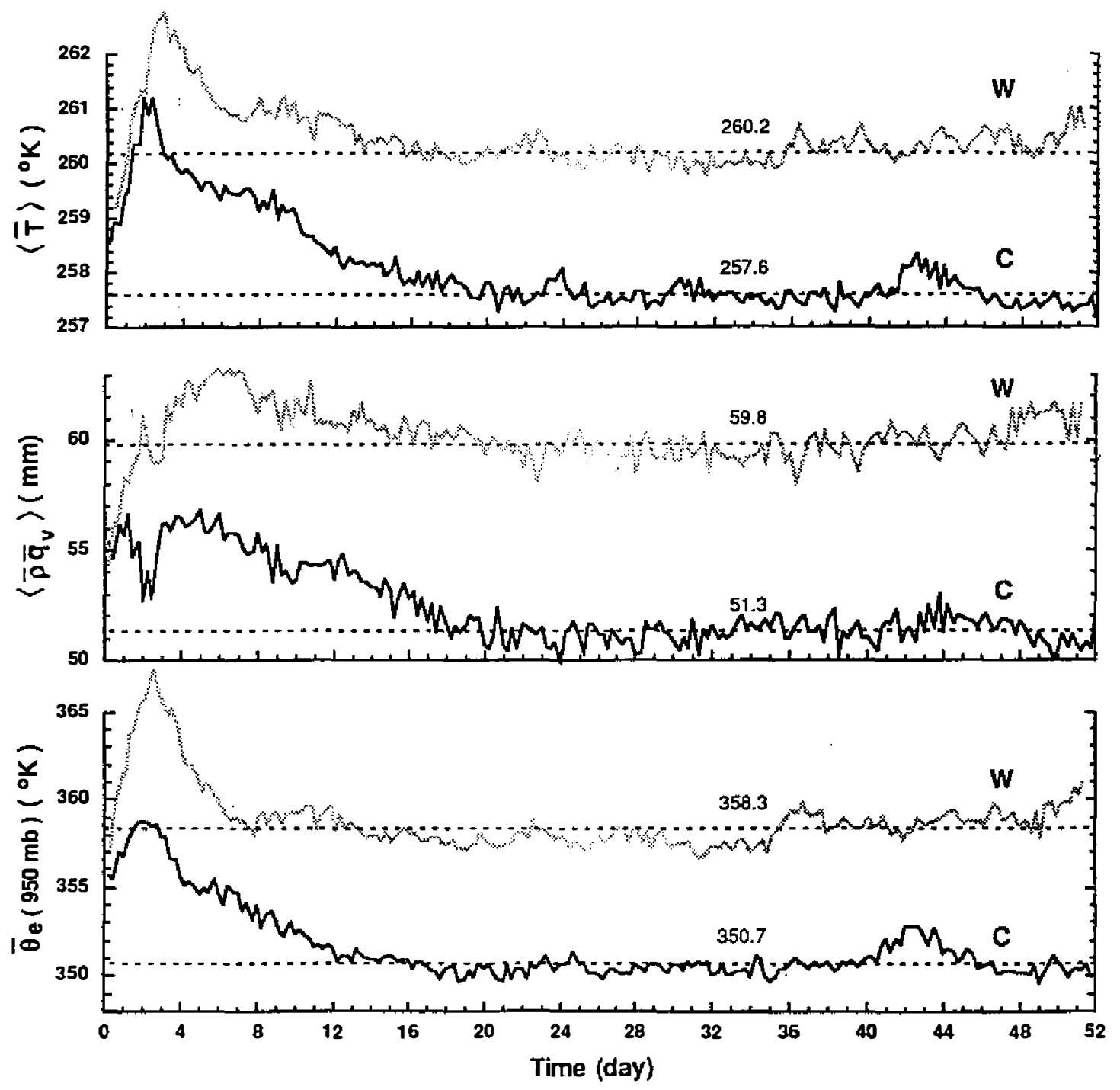

Fig. 17. Time series of the domain averaged temperature, water vapor mixing ratio and $850 \mathrm{mb}$ equivalent potential temperature $\left(\theta_{e}\right)$. 


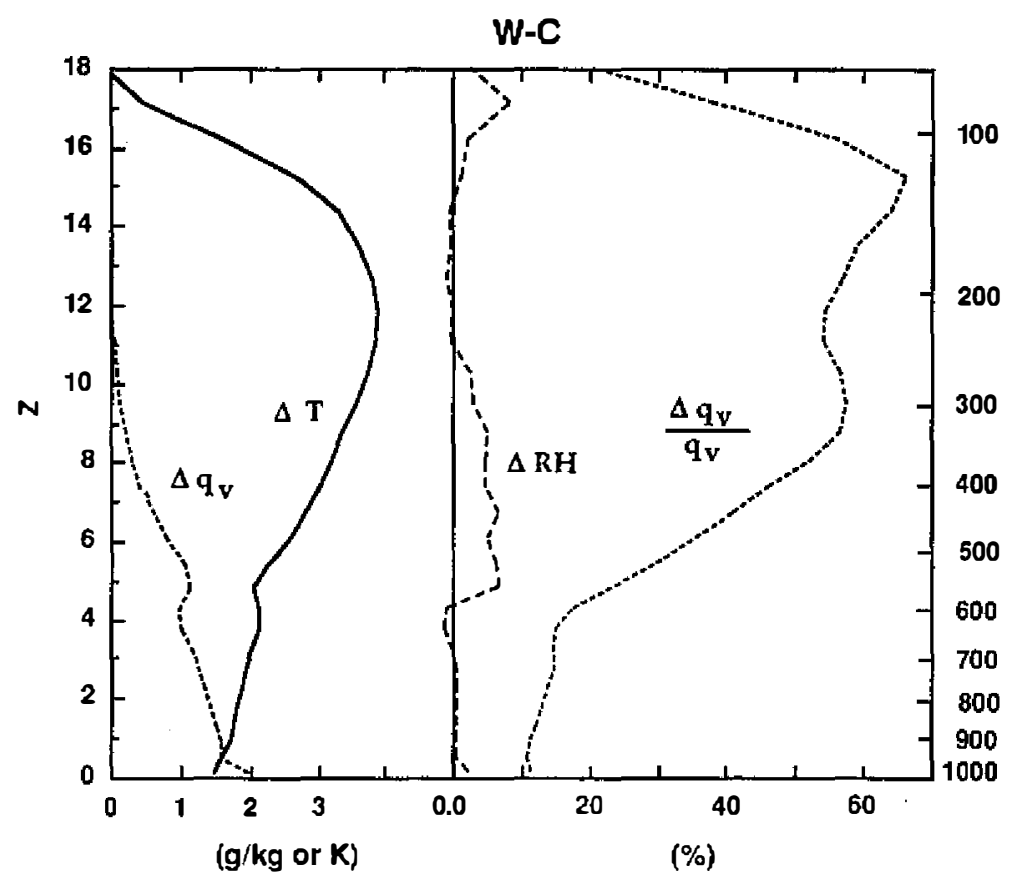

Fig. 18. Difference in vertical distribution of ensemble temperature (T), water vapor mixing ratio $\left(q_{v}\right)$, relative humidity $(\mathrm{RH})$ and percentage change in $q_{v}$, between control and warm cases.

There is much more work to be done comparing simulated cloud systems over various types of land and vegetation environments, ranging from arid to jungle. Solar radiation can play an important role in the cloud-radiation interaction for mid latitude orogenic convective systems (Tripoli and Cotton, 1989), and its effects on the formation and evolution of other types of cloud systems needs to be studied. Our preliminary results have shown that the short-wave radiation is quite sensitive to the parameterization of cloud optical properties. The planned TOGA-COARE and STORM (Stormscale Operational and Research Meteorology) programs should be a good opportunity to orchestrate combined observational and numerical studies of convective systems. In addition, cloud microphysical processes, heat fluxes from the warm ocean and radiative ransfer processes should interact with each other (Section 4.3). How these processes interact under different environmental conditions will be a main focus of modeling studies in the future.

A major area of needed development involves scale interactions and how cloud processes must be included in simulations of mesoscale to global-scale circulation models. Many of the parameterizations for coarse-grid models (except Betts, 1986; using convective adjustment) and virtually all of the parameterizations in mesoscale models, estimate the effects of convection using some type of cloud model. A one-dimensional, steady-state plume or parcel model with a height-independent radius has been widely used in cumulus parameterization (Arakawa and Schubert, 1974; Anthes, 1977; Fritsch and Chappell, 1980; Frank and Cohen, 1985). Several physical properties of clouds, such as the ratio of updraft/downdraft mass 
fluxes, liquid water loading in updraft and downdraft, a method to distribute rain water between updraft, downdraft and the cloud environment, a mechanism to determine cloud size or mass fluxes and vertical shear of the horizontal wind, must be taken into account by the one-D cloud models.

A successful simulation of cloud activity by a mesoscale model is critically dependent on these predetermined parameters used in the cumulus parameterization (Cohen and Frank, 1987; Dudhia, 1989). Cloud modeling work (Soong and Tao, 1980; Tao and Soong, 1986; Krueger, 1988; Lafore et al., 1988; Tao and Simpson, 1989b) has shown that the latent heating profile is very close in shape to the mass fux profile. Both need to be represented realistically and properly for various meteorological situations. The approach we plan provides a method for appraising the validity of the convective cumulus parameterization scheme by directly comparing these results with results of convectively explicit simulations. Trajectory and passive tracer analyses such as performed by Tao and Simpson (1989a) and Scala et al. (1990) can give valuable insight into the origin and the entrainment/detrainment properties of the updraft and downdraft air and the forces acting on air parcels. Cell statistics for size, mass and momentum fluxes such as performed by Tao, Simpson and Soong (1987) should provide a more concrete appraisal of the assumptions used in parameterization schemes, which is greatly needed by the GCM and climate modeling communities.

Acknowledgments The authors thank Dr. S.-T. Soong, Dr. B. Ferrier, Dr. J. Scala, Mr. S. Lang, Dr. M. Yeh, Dr. R. Adler, Dr. C.-H. Sui, Dr. W. Lau, Dr. K. Pickering, Dr. A. Thompson, Dr. C. Kummerow, Dr. M. Moncrieff and Dr. C.-S. Chen for reading the manuscript and for providing many useful suggestions.

The Goddard Cumulus Ensemble Model group is supported by the NASA Headquarters Radiation, Dynamics and Hydrology Branch under Contract 460-23-54 and by NASA TRMM project under Contract 460-63-58. These authors are grateful to Drs. J. Theon and R. Kakar for their support of this research. Acknowledgment is also made to NASAV Goddard Space Flight Center for computer time used in the research.

\section{REFERENCES}

Adler, R. F., H.-Y. Yeh, N. Prasad, W.-K. Tao and J. Simpson, 1991: Microwave rainfall simulations of a tropical convective system with a three-dimensional cloud model. $\mathrm{J}$. Appl. Meteor., 30, 924-953.

Adler, R. F., J. Negri, N. Prasad, W.-K. Tao, 1989: Cloud model-based simulations of satellite microwave data and their application to an SSM I algorithm. Fourth Conf. on Satellite Meteorology and Oceanography. San Diego, AMS, J12-J15.

Anthes, R. A., 1977: A cumulus parameterization scheme utilizing a one-dimensional cloud model. Mon. Wea. Rev., 105, 270-286.

Arakawa, A. and W. H. Schubert, 1974: Interaction of a cumulus cloud ensemble with the large-scale environment. Part I. J. Atmos. Sci., 31, 674-701.

Arking, A., 1991: The radiative effects of clouds and their impact on climate. Bull. Amer. Meteor. Soc., 72, 795-813.

Arking, A., 1992: Water vapor and lapse rate feedback: Insight from a one-dimensional climate model.J. Climate, (submitted). 
Bets, A. K., 1986: A new convective adjustunent scheme. I: Observational and theoretical basis. $\mathrm{T}_{B, \mathrm{~s}}$ Quart. J. Roy. Meteor. Soc., 112, 677-692.

Betts, A. K., 1990: Greenhouse warming and the tropical water vapor budget. Bull. Amer. Meteor. Soc., 71, 1465-1467.

Chen, S., and W. R. Cotton, 1988: The sensitivity of a simulated extra-tropical mesoscale convective system to long-wave radiation and ice-phase microphysics. J. Atmos. Sci., 45, 3897-3910.

Chen, Y.-L., and E. J. Zipser, 1982: The role of horizontal advection of hydrometeors in the water budget of a large squall system. Preprints, 12th Conf. on Severe Local Storms, San Antonio, Amer. Meteor. Soc., 355-358.

Chong, M., and D. Hauser, 1989: A tropical squall line observed during the COPT 81 experiment in west Africa. Part II: Water budget. Mon. Wea. Rev., 117, 728-744.

Chong, M. and D. Hauser, 1990: A tropical squall line observed during the COPT 81 experiment in West Africa. Part III: Heat and moisture budgets. Mon. Wea. Rev., 118, 1696-1706.

Churchill, D. D., and R. A. Houze, Jr., 1984: Development and structure of winter monsoon cloud clusters on 10 December 1978. J. Atmos. Sci., 41, 933-960.

Cohen, C., and W. M. Frank, 1987: Simulation of tropical convective system. Part II. Simulations of moving cloud lines. J. Atmos. Sci., 44, 3800-3820.

Cox, S. K. and K. T. Griffith, 1979: Estimates of radiative divergence during Phase III of the GARP Atlantic Tropical Experiment: Part II. Analysis of Phase III results. J. Atmos. Sci., 36, 586-601.

Dudhia, J., 1989: Numerical study of convection observed during the Winter Monsoon Experiment using a mesoscale two-dimensional model. J. Atmos. Sci., 46, 3077-3107.

Frank, W. M., and J. L. M. Bride, 1989: The vertical distribution of heating in AMEX and GATE cloud clusters. J. Atmos. Sci., 46, 3464- 3478.

Frank, W. M., and C. Cohen, 1985: Properties of tropical cloud ensembles estimated using a cloud model and observed updraft population. J. Atmos. Sci., 42, 1911-1928.

Fritsch, J. M., and C. F. Chappell, 1980: Numerical prediction of convectively driven mesoscale pressure systems. Part I: Convective parameterization. J. Atmos. Sci., 37, 1722-1733.

Gallus, W. A., Jr. and R. H. Johnson, 1991: Heat and moisture budgets of an intense mid latitude squall line. J. Atmos. Sci., 48, 122-146.

Gamache, J. F., and R. A. Houze, Jr., 1983: Water budget of a mesoscale convective system in the tropics. J. Atmos. Sci., 40, 1835-1850.

Gray, W. M., and R. W. Jacobsen, 1977: Diurnal variation of deep cumulus convection. Mon. Wea. Rev., 105, 1171-1188.

Houze, R. A., Jr., 1982: Cloud clusters and large-scale vertical motions in the tropics. J. Meteor. Soc. Japan, 60, 396-409.

Johnson, R. H., 1984: Partitioning tropical heat and moisture budgets into cumulus and mesoscale components: Implication for cumulus parameterization. Mon. Wea. Rev., 112, 1656-1665. 
Krueger, S. K., 1988: Numerical simulation of tropical cumulus clouds and their interaction with the subcloud layer. J. Atmos. Sci., 45, 2221-2250.

Kummerow, C., R. A. Mack and I. M. Hakkarinen, 1989: A self-consistency approach to improve microwave rainfall rate estimation from space. J. Appl. Meteor., 28, 869-884.

Lafore, J.-P., J.-L. Redelsperger and G. Jaubert, 1988: Comparison between a threedimensional simulation and Doppler radar data of a tropical squall line: Transport of mass, momentum, heat, and moisture. J. Atmos. Sci., 45, 3483-3500.

Lau, K.-M., and L. Peng, 1987: Origin of low-frequency (intra-seasonal) oscillations in the tropical atmosphere. Part I: The basic theory. J. Atmos. Sci., 42, 950-972.

Lau, K. M., C. H. Sui and W.-K. Tao, 1993: Studies of the tropical hydrologic cycle using the cumulus ensemble model. Bull. Amer. Meteor. Soc., (in press).

Leary, C. A., and R. A. Houze, Jr., 1980: The contribution of mesoscale motions to the mass and heat fluxes of an intense tropical convective system. J. Atmos. Sci., 37, 784-796.

LeMone, M. A., 1983: Momentum, transport by a line of cumulonimbus. J. Atmos. Sci., 40, 1815-1834.

LeMone, M. A., G. M. Barnes and E. J. Zipser, 1984: Momentum flux by lines of cumulonimbus over the tropical oceans. J. Atmos. Sci., 41, 1914-1932.

Lin, Y.-L., R. D. Farley and H. D. Orville, 1983: Bulk parameterization of the snow field in a cloud model. J. Clim. Appl. Meteor., 22, 1065-1092.

Lindzen, R., 1990a: Some coolness concerning global warming. Bull. Amer. Meteor. Soc., 71, 288-299.

Lindzen, R., 1990b: Response to "Greenhouse warming and the tropical water budget". Bull. Amer. Meteor. Soc., 71, 1465-1467.

Lord, S. J., H. E. Willoughby and J. M. Piotrowicz, 1984: Role of a parameterized ice-phase microphysics in an axisymmetric non-hydrostatic tropical cyclone model. J. Atmos. Sci., 41, 2836-2848.

Malkus, J. S. and H. Riehl, 1964: Cloud Structure and Distributions Over the Tropical Pacific Ocean. University of California Press, 229 pp.

Moncrieff, M. W., 1992: Organized convective systems: archetypal models, mass and momentum flux theory, and parameterization. Quart. J. Roy. Meteor. Soc., 118, 819-850.

Mugnai, A., H. J. Cooper, E. A. Smith, and G. J. Tripoli, 1990: Simulation of microwave brightness temperatures of an evolving hail storm at the SSM/I frequencies. Bull. Amer. Meteor. Soc., 71, 2-13.

Pearson, R., Jr., and C. J. Weaver, 1989: Ozone conservation and entrainment in cumulus congestus. J. Atmos. Sci., 46, 2031-2043.

Pickering, K. E., A. M. Thompson, J. R. Scala, W.-K. Tao, J. Simpson, and M. Garstang, 1991: Photochemical ozone production in Tropical squall line convection during NASA/ GTE/ABLE 2A. J. Geophys. Res., 96, 3099-3114.

Pickering, K. E., A. M. Thompson, J. R. Scala, W.-K. Tao, and J. Simpson, 1992a: Ozone production potential following convective redistribution of biomass emissions. J. Atmos. Chem., 14, 297-313. 
Pickering, K. E., J. Scala, A. M. Thompson, W.-K. Tao and J. Simpson, 1992b: A regional estimate of convective transport of CO from biomass burning, Geophys Res. Letters., Vol. 19, No. 3, 289-292.

Pickering, K. E., A. M. Thompson, J. Scala, W.-K. Tao, R. R. Dickerson and J. Simpson, 1992c: Free tropospheric ozone production following entrainment of urban plumes into deep convection, J. Geophys Res., 97, 17985-18000.

Rutledge, S. A., 1986: A diagnostic modeling study of the stratiform region associated with a tropical squall line. J. Atmos. Sci., 43, 1356-1377.

Rutledge, S. A., and R. A. Houze, Jr., 1987: A diagnostic modeling study of the trailing stratiform rain of a mid latitude squall line. J. Atmos. Sci., 44, 2640-2656.

Scala, J., M. Garstang, W.-K. Tao, K. Pickering, A. Thompson, J. Simpson, V. Kirchhoff, E. Browell, G. Sachse, A. Torres, G. Gregory, R. Rasmussen and M. Khalil, 1990: Cloud draft structure and trace gas transport. J. Geophys. Res., 95, 17015-17030.

Schlesinger, R. E., 1990: Feedback of deep moist convection to its environment as diagnosed from three-dimensional numerical cloud model output: Results from an early experiment. J. Atmos. Sci., 47, 1390-1411.

Schneider, E. K., and R. S. Lindzen, 1976: A discussion of the parameterization of momentum exchange by cumulus convection. J. Geophys. Res., 81, 3158-3161.

Simpson, J., 1980: Downdrafts as linkages in dynamic cumulus seeding effects. J. Appl. Meteor., 19, 477-487.

Simpson, J., 1988: Tropical rainfall measuring mission (TRMM): A satellite mission to measure tropical rainfall. Report of the Science Steering Group, J. Simpson, Ed. NASA Publ., Govt. Printing Office, Washington, DC, 94 pp.

Simpson, J., R. F. Adler, and G. R. North, 1988: A proposed satellite tropical rainfall measuring mission (TRMM). Bull. Amer. Meteor. Soc., 69, 278-295.

Simpson, J., N. E. Westcott, R. J. Cleman and R. A. Pielke, 1980: On cumulus mergers. Arch. Meteor. Geophys. Bioklim., A29, 1-40.

Soong, S.-T., and Y. Ogura, 1980: Response of tradewind cumuli to large-scale processes. J. Atmos. Sci., 37, 2035-2050.

Soong, S.-T., and W.-K. Tao, 1980: Response of deep tropical clouds to mesoscale processes. J. Atmos. Sci., 37, 2016-2036.

Soong, S.-T., and W.-K. Tao, 1984: A numerical study of the vertical transport of momentun in a tropical rainband. J. Atmos. Sci., 41,1049-1061.

Stevens, D. E., R. S. Lindzen and L. J. Shapiro, 1977: A new model of tropical waves incorporating momentum mixing by cumulus convection. Dyn. Atmos. Oceans, 1, 365-425.

Sui, C.-H., K.-M. Lau, W.-K. Tao, J. Simpson and M.-D. Chou, 1993a: Simulated heat, water and radiation budgets in the tropics. Part I: Model responses in a convective regime. $J$. Atmos. Sci., (submitted).

Sui, C.-H., K.-M. Lau, W.-K. Tao and J. Simpson, 1993b: Simulated heat, water and radiation budgets in the tropics. Part II: Climate implication. J. Atmos. Sci., (to be submitted).

Tao, W.-K., 1983: A numerical study of the structure and vertical transport properties of a tropical convective system. Ph.D. Dissertation, Department of Atmospheric Science, University of Illinois, $228 \mathrm{pp}$. 
Tao, W.-K., S. Lang, J. Simpson and R. Adler, 1993: Further development and testing of the heating retrieval algorithms for TRMM. J. of Meteor. Soc. of Japan, (submitted).

Tao, W.-K., and J. Simpson, 1984: Cloud interactions and merging: Numerical simulations. J. Atmos. Sci., 41, 2901-2917.

Tao, W.-K., and J. Simpson, 1989a: A further study of cumulus interaction and mergers: Three-dimensional simulations with trajectory analyses.J. Atmos. Sci., 46, 2974-3004.

Tao, W.-K., and J. Simpson, 1989b: Modeling study of a tropical squall-type convective line. J. Atmos. Sci., 46, 177-202.

Tao, W.-K., and J. Simpson, 1993: The Goddard Cumulus Ensemble Model. Part I: Model description. Terrestrial, Atmospheric and Oceanic Sciences, 4, 35-72.

Tao, W.-K., J. Simpson and M. McCumber, 1989: An ice-water saturation adjustment. Mon. Wea. Rev., 117, 231-235.

Tao, W.-K., J. Simpson, and S.-T. Soong, 1987: Statistical properties of a cloud ensemble: A numerical study. J. Atmos. Sci., 44, 3175-3187.

Tao, W.-K., J. Simpson, S. Lang, M. McCumber, R. Adler and R. Penc, 1990: An algorithm to estimate the heating budget from vertical hydrometeor profiles. J. Appl. Meteor., 29, $1232-1244$.

Tao, W.-K., and S.-T. Soong, 1986: A study of the response of deep tropical clouds to mesoscale processes: Three-dimensional numerical experiments. J. Atmos. Sci., 43, 2653-2676.

Tao, W.-K., J. Simpson and S.-T. Soong, 1991: Numerical simulation of a subtropical squall line over Taiwan Strait. Mon. Wea. Rev., 119, 2699- 2723.

Tao, W.-K., J. Simpson, C.-H. Sui, S. Lang, J. Scala, B. Ferrier, M.-D. Chou and K. Pickering, 1993: Heating, moisture and water budgets of tropical and mid latitude squall lines: Comparisons and sensitivity to long wave radiation. J. Atmos. Sci. 50, 673-690.

Trenberth, K. E., G. W. Branstator and P. A. Arkin, 1988: Origins of the 1988 North American drought. Science, 242, 1640-1645.

Tripoli, G. J., and W. R. Cotton, 1989: Numerical study of an observed orogenic mesoscale convective system. Part 2: Analysis of governing dynamics. Mon. Wea. Rev., 117, 305-328.

Turpeinen, O., 1982: Cloud interactions and merging on day 261 of GATE. Mon. Wea. Rev., 110, 1238-1254.

Westcott, N., 1984: A historical perspective on cloud mergers. Bull. Amer. Meteor. Soc., 65, 219-226.

Willis, P. T., and A. J. Heymsfield, 1989: Structure of the melting layer in mesoscale convective system stratiform precipitation. J. Atmos. Sci., 46, 2008-2025.

Xiang, X., and E. A. Smith, 1992: A simple passive microwave radiative transfer model in a multilayer atmosphere for inversion based precipitation retrieval. J. Appl. Meteor., (submitted).

Yanai, M., S. Esbensen and J. Chu, 1973: Determination of average bulk properties of tropical cloud clusters from large-scale heat and moisture budgets J. Atmos. Sci., 30, 611-627.

Yeh, H.-Y. M., N. Prasad, W.-K. Tao, J. A. Jones, R. Meneghini, and R. F. Adler, 1992: Infrared, microwave, and spaceborne radar simulations of a deep convective system using a 3-D cloud ensemble model. Sixth Conference on Satellite Meteorology and Oceanography, Jan. 5-10, 199.2, Atlanta, Ga, 226-229.

Yeh, H.-Y. M., N. Prasad, R. A. Mack and R. F. Adler, 1990: Aircraft microwave observations and simulations of deep convection from 18-183 GHz. Part II: Model results. J. Atmos. Oceanic Technol., 7, 392-410. 
